\title{
The mammalian centrosome and its functional significance
}

\author{
Heide Schatten
}

Accepted: 2 April 2008 / Published online: 24 April 2008

(C) Springer-Verlag 2008

\begin{abstract}
Primarily known for its role as major microtubule organizing center, the centrosome is increasingly being recognized for its functional significance in key cell cycle regulating events. We are now at the beginning of understanding the centrosome's functional complexities and its major impact on directing complex interactions and signal transduction cascades important for cell cycle regulation. The centrosome orchestrates entry into mitosis, anaphase onset, cytokinesis, G1/S transition, and monitors DNA damage. Recently, the centrosome has also been recognized as major docking station where regulatory complexes accumulate including kinases and phosphatases as well as numerous other cell cycle regulators that utilize the centrosome as platform to coordinate multiple cell cyclespecific functions. Vesicles that are translocated along microtubules to and away from centrosomes may also carry enzymes or substrates that use centrosomes as main docking station. The centrosome's role in various diseases has been recognized and a wealth of data has been accumulated linking dysfunctional centrosomes to cancer, Alstrom syndrome, various neurological disorders, and others. Centrosome abnormalities and dysfunctions have been associated with several types of infertility. The present review highlights the centrosome's significant roles in cell cycle events in somatic and reproductive cells and discusses centrosome abnormalities and implications in disease.
\end{abstract}

Keywords Centrosomes - Microtubules - Cell cycle · Mitosis - Centrosome proteins · Centrosome functions · MTOC

H. Schatten ( $\square)$

Department of Veterinary Pathobiology, University of Missouri, 1600 E Rollins Street, Columbia, MO 65211, USA

e-mail: SchattenH@missouri.edu

\section{Introduction}

Over 120 years have passed since the discovery of centrosomes (Flemming 1875; Van Beneden 1876) and yet, we are only at the beginning of understanding the multiple and central roles of this intriguing cellular organelle. Boveri (1901) who coined the name centrosomes had produced a remarkable wealth of new information characterizing and analyzing centrosomes during fertilization and cell division (Boveri 1901) by using iron hematoxylin as a major cytological staining technique, and he brilliantly recognized the very important role of centrosomes in cancer (1914). Flemming had called the discovery of centrosomes as important as the discovery of the nucleus (Flemming 1891) yet, research on centrosomes stagnated for decades for a number of reasons including war events in Europe that slowed all research and because studies using the electron microscope did not reveal a structure that could be easily defined. Centrosome structure was described as amorphous osmiophilic material surrounding a pair of well-structured centrioles, which stimulated and generated new research on centrioles while research on centrosomes became less appreciated. With the development of immunological probes and molecular techniques coupled with immunofluorescence microscopy centrosomes reclaimed their status and Boveri's earlier work was vigorously pursuit by reproductive biologists, and by cellular and cancer biologists who were able to confirm and build on Boveri's remarkably detailed and accurate data and visionary research. Our understanding of centrosomes has advanced enormously and very rapidly in recent years and its central role in cellular biology has clearly been recognized. It can be predicted that a number of diseases other than cancer are linked directly or indirectly to centrosome dysfunctions. Centrosome isolations, forward and reverse genetics, RNA-mediated 
interference, mass-spectrometry-based proteomics, live cell imaging particularly with GFP-tagged proteins, and laser microsurgery are some of the newer more recently employed techniques that have been applied to centrosome research and rapidly moved the field into new frontiers. The present paper will review the state of our knowledge of centrosomes and analyze its impact on cellular functions.

\section{Definition of the centrosome and its key functions}

The centrosome is a subcellular non-membrane bound semiconservative organelle, approximately $1 \mu \mathrm{m}$ in size, that serves as the cell's primary microtubule organizing center (MTOC) and plays a major role in numerous cellular functions. Through its microtubule organizing functions the centrosome facilitates many cellular activities including cell motility, polarity, maintenance of cell shape, cell division, transport of vesicles, and targeting of numerous signaling molecules. A typical mammalian centrosome consists of a proteinaceous scaffold containing a large number of centrosome proteins including $\gamma$-tubulin and the gamma-tubulin complex $(\gamma$-TuRC) that typically surround a pair of perpendicularly oriented cylindrical centrioles, therefore referred to as pericentriolar material (PCM). The PCM scaffold undergoes shape changes throughout the cell cycle to produce cell-cycle-specific microtubule organizations for specific cellular functions. Lacking a defined membrane boundary, the centrosome's three-dimensional architecture is maintained through specific protein-protein interactions. Microtubules are anchored at the centrosome with their minus ends (Bornens 2002) and microtubule growth is regulated by distal plus-end addition of tubulin subunits (McIntosh and Euteneuer 1984). In interphase, the centrosome is juxtapositioned and closely associated with the nucleus. At the G2/M transition it undergoes significant cell cycle-specific reorganizations and matures into the division-competent center of the mitotic poles. Because the centrosome nucleates microtubules and controls microtubule numbers and lengths it directs most microtubule-related functions including transport of macromolecular complexes, positioning of cell organelles, cell motility, cell shape, polarity, and segregation of chromosomes during cell division. The mitotic centrosomes are critically important to mediate the strictly balanced bipolar separation of chromosomes. In addition to the regular function as MTOC the centrosome orchestrates various major important cell cycle events including entry into mitosis, anaphase onset, cytokinesis, G1/S transition, and monitoring of DNA damage (Kramer et al. 2004).

While a typical centrosome consists of a pair of centrioles surrounded by PCM, centrioles are not always present within the centrosome structure as will be detailed later in this paper. In general, centrioles are important for centro- some integrity and to aid in the recruitment of centrosomal proteins into the PCM. The PCM is a fibrous scaffolding lattice that consists of a large amount of coiled-coil centrosome proteins and anchors signaling molecules and components of the $\gamma$-TuRC (Fig. 1). Some centrosome proteins are permanently associated with the centrosome core structure such as $\gamma$-tubulin, the $\gamma$-TuRC, and centrin (addressed below in more detail) while several other centrosomal proteins are temporarily associated with the centrosome core structure and include centrosome proteins such as the Nuclear Mitotic Apparatus protein (NuMA). Such centrosomal proteins serve cell-cycle-specific functions and are needed for specific cell cycle activities. The cell cycle-specific centrosome proteins are different from those proteins or enzymes (kinases, phosphatases and others) that may be colocalized with centrosomes and may utilize centrosomes as a docking station but are not centrosome proteins that are directly involved in performing centrosome-specific functions. So far, about 500 different proteins have been associated with the centrosome by mass spectroscopy (Andersen et al. 2003) although it is not clear whether all of those proteins are centrosome proteins or proteins or enzymes that use centrosomes as docking station. Regulators of various cell cycle events have been co-localized with centrosomes and include the mitogen activated protein kinase (MAPK) (Sun et al. 2002) which may use centrosomes as a docking station to perform and coordinate multiple cell cycle-specific functions. Vesicles that are translocated along microtubules to and away from centrosomes may also carry enzymes or substrates that use centrosomes as docking platform (Fig. 2a, b).

Functional homologues of centrosomes are spindle pole bodies of yeast (Knop et al. 1999), the nucleus-associated body of the cellular slime mold (Daunderer et al. 1999), and nucleating sites in plants (Chan et al. 2003). In addition, multiple plasma membrane-associated sites in Drosophila epidermal cells (Mogensen 1999) and in Xenopus oocytes (Pfeiffer and Gard 1999) have also been identified to serve as MTOCs. New research has established that virus, bacteria, and parasites exploit the host cell's centrosomal capabilities and recruit centrosomal material for their own survival within host cells (reviewed in Scaplehorn and Way 2004; Coppens et al. 2006).

Taken together, the centrosome is a truly central and main cellular station that directs, coordinates, and regulates most cellular functions either directly or indirectly through its microtubule organizing capabilities.

\section{Centrosome proteins and their specific functions}

Numerous centrosome proteins have been described and their functions have been determined but the list of newly discovered centrosome proteins continues to grow and 




Fig. 1 A typical mammalian centrosome is composed of two centrioles surrounded by a meshwork of a proteins embedded in matrix called the pericentriolar material (PCM). Gamma-tubulin and the gamma-tubulin ring complex that nucleate microtubules along with associated proteins are embedded in the PCM. Highlighted in this diagram are two centrosomal complexes, the microtubule nucleating complex and the microtubule anchoring complex

includes centrosome proteins that have multifunctional capabilities. Furthermore, the list of diseases in which centrosome protein dysfunctions play a role also continues to grow as research on centrosomes has progressed rapidly and new research teams have formed around the growing centrosome field. The initial discovery of centrosomal proteins in an autoimmune antibody has provided a most powerful tool to stain centrosomes with immunological probes (Calarco-Gillam et al. 1983) and since then, a large number of centrosomal proteins have been identified based on purification of autoimmune sera and subsequent production of specific centrosome antibodies.

The reported number of centrosome proteins varies depending on the methods applied. Because the centrosome is a non-membrane-bound organelle it does not have defined borders and isolation methods can be flawed by removing critical centrosome proteins or including contaminants that are not centrosome proteins. In addition, because the centrosome is a flexible structure that undergoes cell cycle-specific changes the number of centrosome proteins varies in different cell cycle stages. Functional screens have been used but because of the nature of centrosomes may not detect all centrosome proteins. Mass spectroscopy has identified as many as 500 centrosomal proteins (Andersen et al. 2003) while a more conservative
A
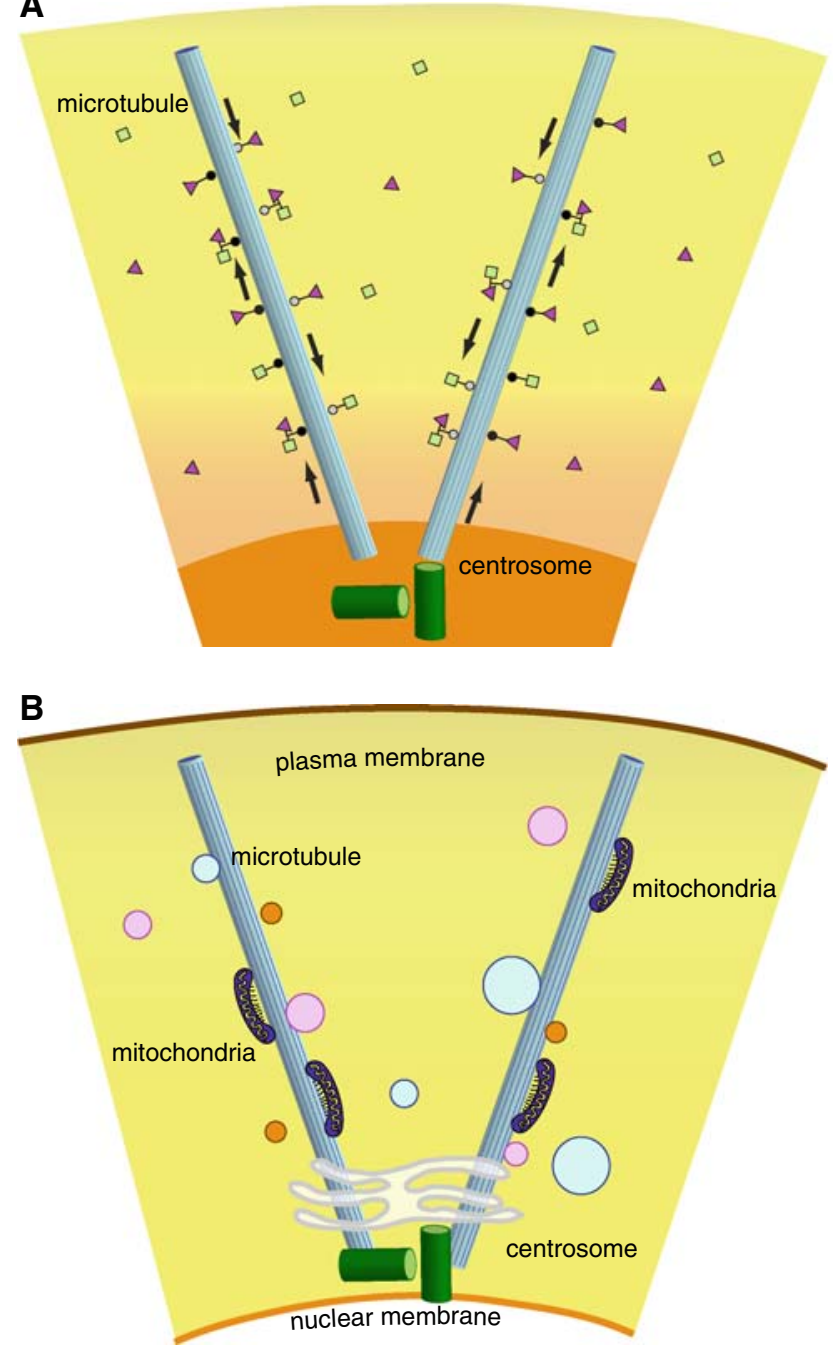

Fig. 2 a The centrosome serves as central station to mediate substrate and enzyme activities along microtubules towards the minus ends of microtubules driven by dynein (white circles) and toward the plus ends driven by kinesin (black circles). b Through its microtubule-organizing capabilities the centrosome mediates distribution of cell organelles such as mitochondria, Golgi, and vesicles of various sizes, many containing regulatory enzymes for cell cycle regulation

number of 100 have been identified with different methods at various cell cycle stages with about 60 being present in the interphase centrosome (reviewed by Wilkinson et al. 2004) and may reflect the average centrosome protein quantities that are characteristic for interphase centrosomes in typical mammalian somatic cells. Various definitions have been used to describe the centrosome. It is generally agreed that the centrosome core structure consists of permanently associated centrosome proteins that remain after treatment of the centrosome complex with microtubule depolymerizing agents such as cold, nocodazole, colchicine derivatives, and others. The well-studied $\gamma$-tubulin is a protein of the centrosome core structure. Centrosome core proteins are permanently associated with the centrosome 
structure throughout cell cycle-dependent structural changes in most systems. Such cell cycle-specific changes are particularly apparent in reproductive cells after fertilization in, which rapid changes of centrosomes and microtubule formations are required for rapid cell cycle functions. Other centrosome proteins associate with the core structure during different cell cycle stages to perform cell cycle-specific functions (discussed below). Such proteins include NuMA (reviewed in Sun and Schatten 2006) that performs essential functions in mitosis. The analysis of determining the number of centrosome proteins is further complicated by the great number of proteins that use centrosomes as a central docking station or platform where regulatory complexes accumulate and communicate by signaling through the microtubule network. Such complexes may co-localize with centrosomes but should not be included in the definition of the centrosome. Known and newly identified centrosome proteins that localize to human centrosomes are reviewed in Wilkinson et al. (2004). Centrosome proteins that are known to be present in purified centrosomes and identified by mass spectrometric analysis include the structural proteins alpha tubulin, beta tubulin, gamma-tubulin, gamma-tubulin complex components 1-6, centrin 2 and 3, AKAP450, pericentrin/ kendrin, ninein, pericentriolar material 1 (PCM1), ch-TOG protein, C-Nap1, Cep250, Cep2, centriole-associated protein CEP110, Cep1, centriolin, centrosomal P4.1 associated protein (CPAP), CLIP-associating proteins CLASP1 and CLASP 2, ODF2, cenexin, Lis1, Nudel, EB1, centractin, myomegalin; the regulatory molecules cell division protein 2 (Cdc2), Cdk1, cAMP-dependent protein kinase type IIalpha regulatory chain, cAMP-dependent protein kinasealpha catalytic subunit, serine/threonine protein kinase Plk1, serine/threonine-protein kinase Nek2, serine/threonine-protein kinase Sak, Casein kinase I, delta and epsilon isoforms, protein phosphatase $2 \mathrm{~A}$, protein phosphatase 1 alpha isoform, 14-3-3 proteins, epsilon and gamma isoforms; the motor and related proteins dynein heavy chain, dynein intermediate chain, dynein light chain, dynactin 1 , p150 Glued, dynactin 2, p50, dynactin 3; and the heat shock proteins heat shock protein Hsp90, TCP subunits, and heat shock protein Hsp73.

Centrosomes can be depleted of many PCM components by treatment with high salt which also extracts $\gamma$-tubulin (Moritz et al. 1998) leaving behind centrosome scaffolds. A centrosome matrix has been described in several studies and has been visualized in the classic sea urchin invertebrate model system with low voltage field emission scanning electron microscopy (LVFESEM) on cold treated and isolated centrosomes (Thompson-Coffe et al. 1996; reviewed in Schatten et al. 2000a; Schatten and Chakrabarti 2004), which revealed a particle structure of 1-2 $\mu \mathrm{m}$ and repeating subunits.
Centrosome proteins that have been studied more fully in various cell systems include $\gamma$-tubulin, pericentrin, centrin, and NuMA.

Gamma-tubulin is an essential centrosome protein which had been discovered through fungal genetics (Oakley and Oakley 1989) and since then described in all eukaryotic cell groups. Gamma tubulin is not only found in centrosomes but it also can serve as nucleating sites in animal cells that do not display typical centrosomes (Tulu et al. 2003). Gamma-tubulin is localized at the oocyte cortex in amphibians which has been shown by Pfeiffer and Gard (1999). In plants that do not have typical centrosomes, $\gamma$-tubulin is thought to nucleate unfocused microtubules within the cell and it is found along the length of microtubules (Canaday et al. 2000). Gamma-tubulin is a highly conserved protein in eukaryotes. It is vital for centrosome functions and elimination of $\gamma$-tubulin is lethal to cells and to the organism (Oakley et al. 1990; Joshi et al. 1992) while elimination of components that bind to $\gamma$-tubulin has little effect on cell viability. The function of $\gamma$-tubulin was clearly determined by purification of the $\gamma$-tubulin ring complex $(\gamma$-TuRC) that revealed a ring shape and a substructure that were able to nucleate microtubule polymerization in vitro (Zheng et al. 1995). The ca. 2.2-MDa $\gamma$-TuRC consists of 12 or 14 $\gamma$-tubulin molecules and is the nucleating complex for microtubules in all cells studied so far (Hannak et al. 2002). Gamma tubulins may laterally interact with each other. Several accessory proteins are associated with this complex (Tassin and Bornens 1999; Gunawardane et al. 2000; Murphy et al. 2001) providing new challenges for further investigations. The $\gamma$-TuRC has been well characterized by electron microscopy including immunoelectron tomography showing an open ring structure of ca. $25 \mathrm{~nm}$ diameter (Moritz et al. 1995; Zheng et al. 1995; Oegema et al. 1999; Moritz et al. 2000). The $\gamma$-TuRC is capable of functionally capping the minus ends of microtubules facilitating growth of microtubule protofilaments. Six components of the $\gamma$-TuRC in addition to $\gamma$-tubulin have been identified so far (Gunawardane et al. 2003; Murphy et al. 2001; Tassin et al. 1998). Gamma-tubulin complexes are required for microtubule assembly which has been shown by using saltextracted centrosomes that lack $\gamma$-TuRCs and are not able to recruit microtubules while addition of $\gamma$-tubulin complexes from cytoplasmic extracts restored nucleation competency although various other components are needed to anchor the $\gamma$-TuRC to the centrosome structure including the large coiled-coil A-kinase anchoring proteins (Tassin et al. 1998; Murphy et al. 1998; Dictenberg et al. 1998; Doxsey et al. 1994; Flory and Davis 2003; Gillingham and Munro 2000; Kawaguchi and Zheng 2004; Keryer et al. 2003; Steadman et al. 2002; Takahashi et al. 2002) and Cep135 (Ohta et al. 2002). The microtubule-minus-endbinding proteins including $\gamma$-TuRC are concentrated at the 
proximal ends of centrioles while tubulin polyglutamylation of the centriole walls modulates interaction between tubulin and microtubule associated proteins. The centrioleinteracting proteins can bind and aid in the recruitment of matrix proteins.

A cell cycle-dependent regulation of $\gamma$-TuRC is thought to account for differences between interphase and mitotic microtubule structure formations and activities. In interphase $\gamma$-TuRC nucleates fewer but longer microtubules while in mitosis, more $\gamma$-TuRC is associated with the centrosome, which is part of the centrosome maturation process that takes place from interphase to mitosis (discussed below). Mitotic microtubules are shorter, larger in number, and highly dynamic. They are regulated by a number of cell cycle-specific proteins that participate in centrosome regulation such as the small GTPase Ran, Aurora A kinase, polo-like kinases and others.

Pericentrin is a centrosome protein that plays a role in centrosome and spindle organization (Doxsey et al. 1994; Dictenberg et al. 1998; Young et al. 2000). It forms a ca. 3 MDa-complex with $\gamma$-tubulin and depends on dynein for assembly onto centrosomes (Young et al. 2000). Pericentrin plays a role in recruiting $\gamma$-tubulin to centrosomes in vertebrate cells (Dictenberg et al. 1998) along with several other proteins; it is part of the pericentrin/AKAP450 centrosomal targeting (PACT) domain (Gillingham and Munro 2000). Mutation of the pericentrin gene results in loss of recruitment of several other centrosomal proteins aside from $\gamma$-tubulin, which argues for its essential role in the centrosome complex; it may provide a link between centrioles and centrosomes (Martinez-Campos et al. 2004).

Centrins are small proteins and members of a highly conserved subgroup of the EF-hand superfamily of $\mathrm{Ca}^{2+}$ binding proteins that is associated with centrioles (Bornens 2002; Jurczyk et al. 2004). Centrin is also an intrinsic component of centrosomes that has an essential role in the duplication of centrosomes (Levy et al. 1996; Salisbury 1995; Lutz et al. 2001; reviewed in Manandhar et al. 2005) which has been clearly determined in mutation experiments (Salisbury et al. 2002).

NuMA (Nuclear Mitotic Apparatus protein) is an essential cell cycle-dependent centrosome-associated protein that plays a significant role in the organization of the mitotic apparatus during mitosis. It is a multifunctional protein (reviewed in Sun and Schatten 2006, 2007) that performs nuclear functions as nuclear matrix protein during interphase and translocates from the nucleus to spindle poles at the onset of mitosis to form a crescent-shaped complex around centrosomes tethering microtubules into the accurate bipolar organization (addressed below in more detail).

Many of the other centrosomal proteins also play significant roles in centrosome functions but are not discussed in detail in this section. Several centrosomal proteins have been implied in microtubule anchoring to the centrosome including ninein that has strongly been implied to serve as microtubule minus-end anchoring protein (Mogensen et al. 2000) and dynactin that has a major role in microtubule anchorage at centrosomes as well as at non-centrosomal anchorage sites. It is preferentially localized to the mother centriole and plays a role in microtubule organization (Quintyne et al. 1999; Schroer 2001; Quintyne and Schroer 2002).

\section{Centrosome cycle within the cell cycle}

Live cell imaging and immunofluorescence microscopy have clearly shown the remarkable shape changes of the centrosome which is best visualized in reproductive cells after fertilization requiring rapid centrosome and microtubule dynamics to position the pronuclei and prepare the zygote cell for mitosis. Figure 3 shows stages of the centrosome cycle in a sea urchin egg which is the model system used by Boveri (1901) for many of his centrosome studies. Centrosomal material disperses around the zygote nucleus (Fig. 3a) to become bipolar in late prophase (Fig. 4c). It becomes maximally condensed during metaphase (Fig. 3e) and expands within the anaphase spindle poles (Fig. 3g) before it becomes compacted again when telophase nuclei form. Figure 3b, d, f, and $h$ are images of microtubule labeling for either the same cell or cells of equivalent cell cycle stages.

In interphase, a single centrosome containing a pair of centrioles is juxta-positioned and closely connected to the nucleus as shown in Fig. 4 in an LNCaP prostate cancer cell (Fig. 4b), mouse 3T3 cells containing GFP-centrin label to detect centrosomes and labeled with $\alpha$-tubulin to detect microtubules (Fig. 4a, c, d), and a pig fibroblast cell labeled with $\gamma$-tubulin to detect the centrosome and Mitotracker Rosamine to detect mitochondria (Fig. 4e). Centrosomes duplicate shortly before the $\mathrm{G} 2$ stage of the cell cycle in a precisely orchestrated program to ensure precise duplication into two and not more centrosomes. This process begins with disorientation of the pair of centrioles, centriole duplication, centrosome disjunction, and results in sister centrosome separation as reviewed in Mack et al. (2000) and Ou et al. (2004). While a wealth of data has been accumulated on the duplication and separation of centrioles data on the molecular events underlying centrosome duplication, disjunction and separation are only slowly accumulating. Centrosome separation refers to the spatial separation of centrosome material around the nucleus which is driven by plus- and minus-end directed microtubule motor proteins. The Nek2 kinase is involved in centrosome disjunction (Meraldi and Nigg 2001; reviewed by Fry 2002). Phosphorylation of the centrosomal protein centrin plays a role in centrosome disjunction at the $\mathrm{G} 2$ /prophase transition. 



Fig. 3 The structural cell cycle-dependent changes of centrosomes are shown here in sea urchin eggs during the first cell cycle after fertilization. This system had been used by Theodor Boveri for the majority of his classic studies on centrosomes. Centrosome material disperses around the zygote nucleus (a arrows) and separates to the poles during prophase (c arrows). Centrosomes become densely compacted in metaphase (e arrows) and disperse during anaphase (g arrows). The

Polo like kinases are required for multiple stages of mitotic progression and have clearly been implicated in centrosome separation. Specific kinases have been linked to centrosome and microtubule dynamics and Plk1 plays a critical role in centrosome and microtubule organization (Sun et al. 2001a, b, c, d, 2002; Tong et al. 2002, 2003; Fan et al. 2003). Plk1 and Plk3 both have been implicated in microtubule and centrosome functions in interphase and in mitosis (Fenton and Glover 1993; Donaldson et al. 2001; Wang et al. 2002). Loss of Plk3 function has also been associated with loss of cell shape which indicates loss of microtubule functions underneath the plasma membrane (Wang et al. 2002).

While the role of centrosomes in microtubule nucleation and chromosome separation has been studied in great detail, centrosomes have only more recently been implicated in cytokinesis. Khodjakov and Rieder (2001) showed that 30$50 \%$ of cells with laser-ablated centrosomes failed to complete cytokinesis perhaps because spindles formed without orientation and did not have attachment to the cell cortex resulting in incomplete chromosome separation. The molecular mechanisms by which centrosomes exert an effect on cytokinesis are not clear but their role as docking station for cytokinesis-required regulatory proteins is implied and may include Plk and microtubule motor proteins.

The role of centrosomes as docking station where regulatory complexes accumulate for cell cycle activities has only been studied in recent years. The centrosome serves as
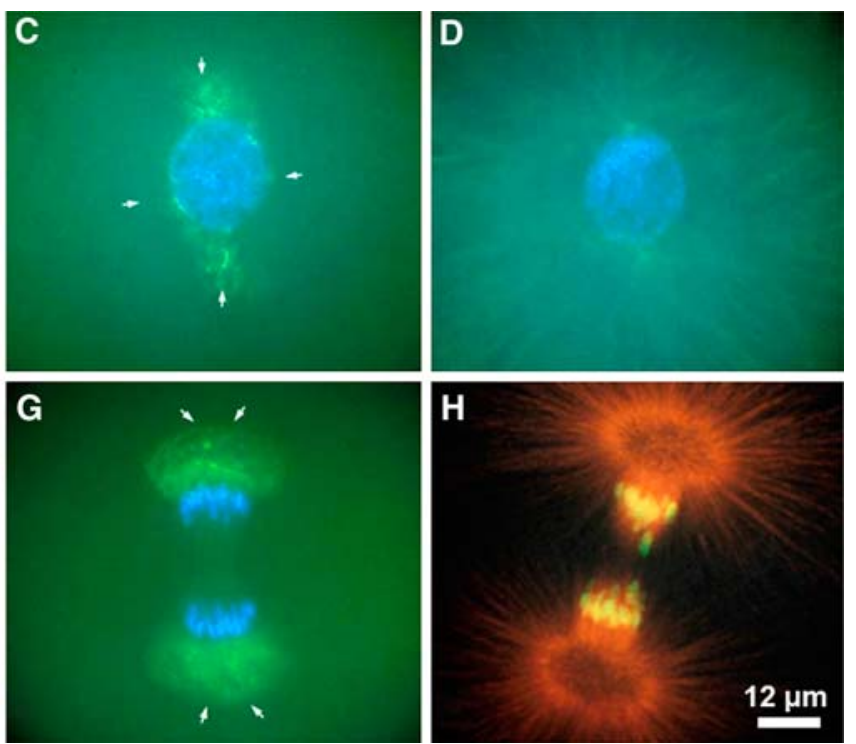

correlated images for microtubules either from the same cell or from corresponding cell cycle stages are shown in $\mathbf{b}, \mathbf{d}, \mathbf{f}$, and $\mathbf{h}$. Immunofluorescence microscopy of centrosomes, microtubules, and DNA (blue). Centrosomes are displayed in green; microtubules are displayed in green $(\mathbf{b}, \mathbf{d})$ or red $(\mathbf{f}, \mathbf{h})$. Reprinted with permission from Schatten et al. 2000a

a platform for a wide variety of regulatory molecules that play a role in cell cycle-specific functions but are not themselves centrosome proteins. These complexes regulate peripheral events through microtubule-dependent transport which indicates a role of the centrosome as command center that integrates signals using microtubules as signaling routes. As such, centrosomes play critical roles in cell cycle regulation in both mitosis and interphase by providing a central signaling station and controls to trigger the next phases of the cell cycle by integrating, regulating, and amplifying signaling pathways.

Phosphorylation and posttranslational modifications are other important aspects in centrosome regulation required for cell cycle-specific changes which has been reviewed in Wilkinson et al. (2004).

Centrosome duplication in a regular cell cyle is typically well synchronized with the DNA cycle. Studies on duplication of centrosomes have been performed in recent years to reveal that there is a block to reduplication which assures that centrosomes are duplicated accurately only once within a normal cell cycle. Elegant studies to determine the block to reduplication have been performed by Wong and Stearns (2003) who fused G1 phase cells containing one centrosome with G2 phase cells containing two centrosomes to determine if an already duplicated centrosome would re-duplicate under these conditions. Interestingly, the $\mathrm{G} 1$ centrosome duplicated while the $\mathrm{G} 2$ centrosome did not which led to the conclusion that there is an intrinsic 
Fig. 4 In interphase, a single centrosome is juxta-positioned to the nucleus. $\mathbf{a}, \mathbf{c}$, and $\mathbf{d}$ show small GFP-centrin-labeled centrosomes in mouse $3 \mathrm{~T} 3$ cells.

Microtubules are detected with $\alpha$-tubulin and shown in red; $\mathbf{b}$ is of an $\mathrm{LNCaP}$ prostate cancer cell labeled with human autoimmune antibody SPJ displaying multiple centrosomal foci perhaps indicating centrosome abnormalities; e shows a porcine fibroblast cell labeled with $\gamma$-tubulin to detect the centrosome and $\mathrm{Mi}$ totracker Rosamine to detect mitochondria. Microtubules are shown in green; $\mathbf{b}$ reprinted with permission from Schatten et al. $2000 \mathrm{~b}$
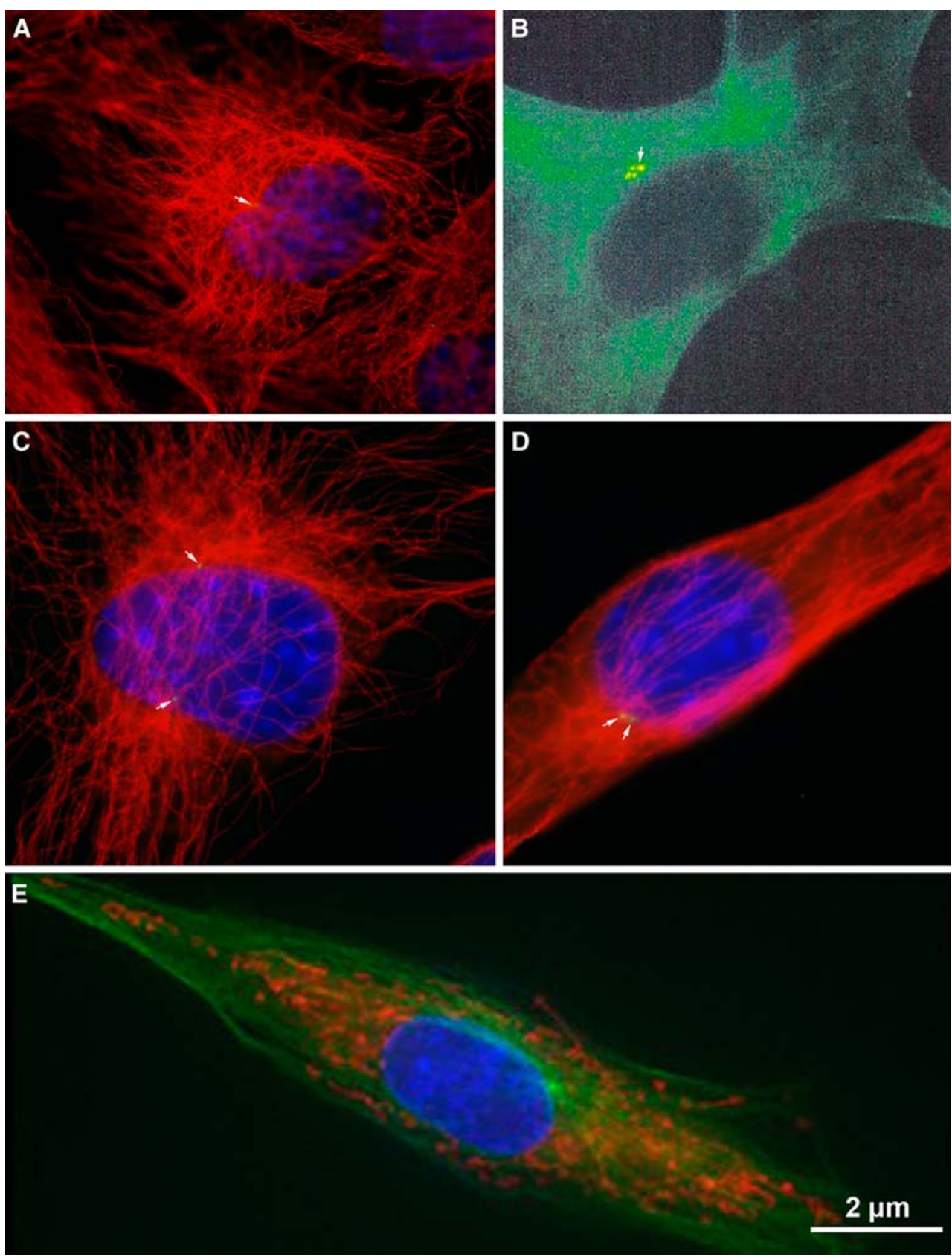

block to reduplication within the centrosome. Initiation of centrosome duplication is under cytoplasmic control and driven by cyclin-dependent kinase 2 ( $\mathrm{Cdk} 2)$ complexed with cyclin $\mathrm{E}$ or cyclin A that rises during the late G1 stage (reviewed in Sluder 2004). These results were compiled by several laboratories in the late 1990s using Xenopus eggs (Hinchcliffe et al. 1999; Lacey et al. 1999) and mammalian somatic cells (Mantel et al. 1999; Matsumoto et al. 1999). It was later shown that initiation of centrosome duplication also requires calcium/calmodulin-dependent kinase II (CaMKII) (Matsumoto and Maller 2002). CaMKII phosphorylates centrosome proteins in vitro (Pietromonaco et al. 1995) and is localized to spindle poles (Ohta et al.
1990). Ubiquitin-mediated proteolysis of centrosomal proteins may be involved in the block to reduplication as proposed by several investigators (Tugendreich et al. 1995; Freed et al. 1999; Gstaiger et al. 1999) who showed localization of a variety of components of the SFC proteolysis pathway as well as the 26-S proteasome to centrosomes in human cells.

Centrosome duplication and DNA replication both require hyperphosphorylation of the retinoblastoma (RB) protein and activation of $\mathrm{Cdk} 2$. Although the centrosome cycle and DNA cycle are normally coupled through cell cycle-dependent checkpoints it has been possible to dissociate the centrosome cycle from other cell cycle events. 
Application of cycloheximide to Xenopus oocytes has resulted in centrosome duplication while other cell cycle events were inhibited (Gard et al. 1990). Hydroxyurea or aphidicolin also resulted in continuation of the centrosome cycle in $\mathrm{CHO}$ cells producing supernumerary centrosomes while DNA replication was inhibited (Balczon et al. 1995).

Normally, the DNA cycle and the centrosome cycle are intimately coupled and synchronized in a regular cell cycle. When the nucleus or DNA is damaged, centrosomes become inactivated in a well-orchestrated process. The $\gamma$-TuRC dissociates from centrosomes, the spindle fails to assemble resulting in failure of chromosome segregation. Figure 5 is a schematic representation of a typical centrosome cycle within a typical cell cycle. Please see figure legend for description.

\section{Centrosome maturation into mitotic centrosomes}

One of the most important functions of the centrosome is its role in establishing the bipolar mitotic spindles that orches- trate the precisely balanced segregation of chromosomes. To accomplish this important function a major reorganization of centrosomal material occurs at the $\mathrm{G} 2 / \mathrm{M}$ transition in vertebrate cells which is referred to as centrosome maturation. During this time some centrosomal proteins become diminished while others such as the $\gamma$-TuRC become enriched (Khodjakov and Rieder 1999) and $\gamma$-tubulin increases three to five-fold (Khodjakov and Rieder 1999).

Cyclin-dependent kinases play a significant role in centrosome cycle progression. The $\mathrm{G} 2 / \mathrm{M}$ transition requires $\mathrm{Cdk} 1 /$ cyclin $\mathrm{B}$ as well as $\mathrm{Cdk} 1 /$ cyclin $\mathrm{A}$, which has been reviewed in detail by Fry and Hames (2004). Cdk1 is localized to centrosomes at the onset of mitosis (Bailly et al. 1989; Pockwinse et al. 1997) and it has been shown that Cdk1/ cyclin B activation is detected in centrosomes during prophase (Jackman et al. 2003).

The centrosome cycle is tied to the centriole cycle and both are closely coupled with the DNA cycle. At the transition from the G1 to $\mathrm{S}$ phase centriole duplication begins and continues through $\mathrm{G} 2$ when the replicating pro-centriole elongates. Two duplicated juxta-positioned centrioles are

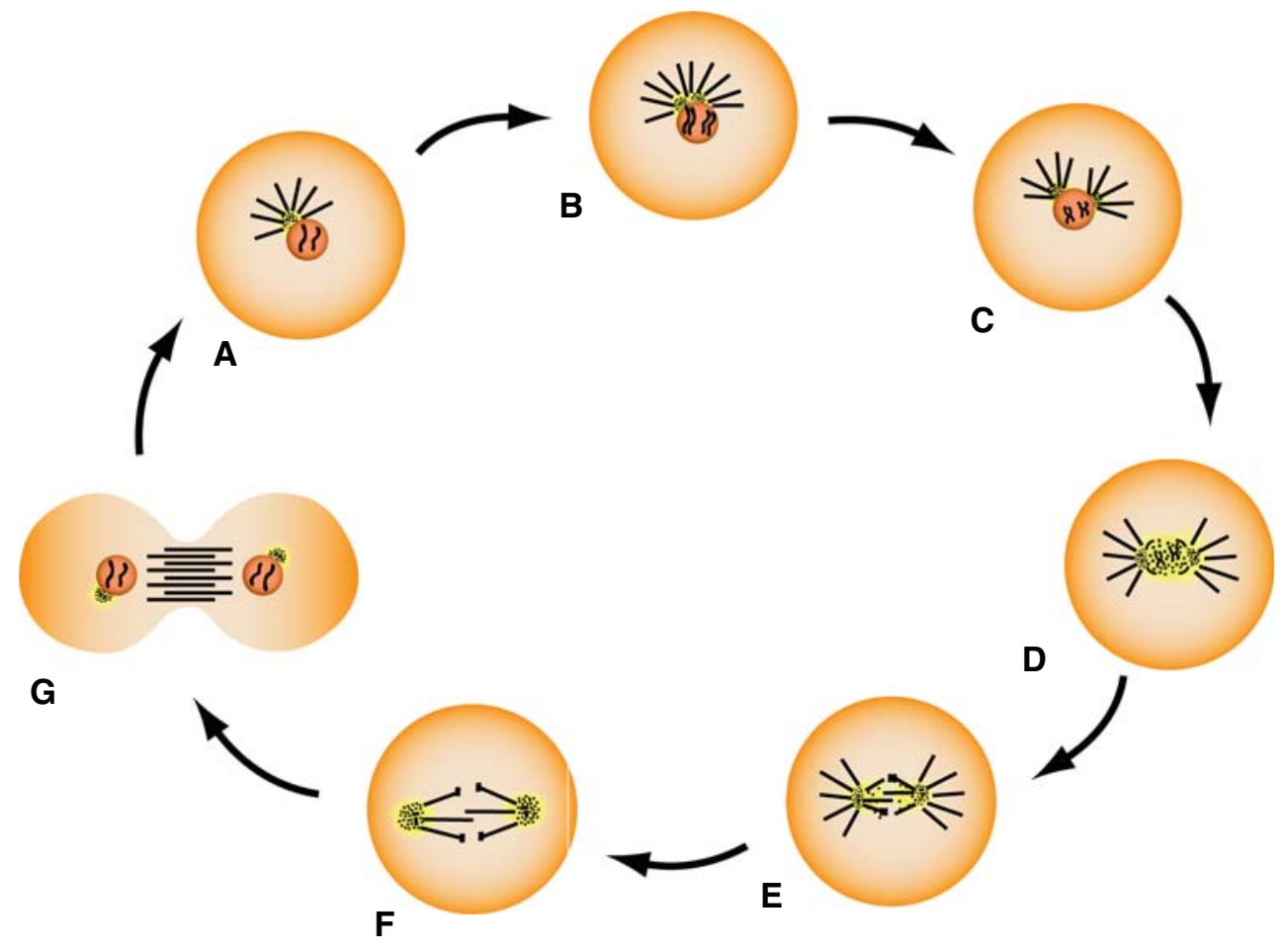

Fig. 5 A typical mammalian centrosome cycle within the cell cycle. The single interphase centrosome (a) is closely associated with the nucleus and nucleates an array of interphase microtubules. Centrosome duplication occurs during the S phase in synchrony with DNA dupliction (b). Centrosome separation of the duplicated centrosome toward opposite poles takes place in the early prophase stage (c). The bipolar mitotic apparatus becomes established when centrosomes have reached the opposite poles and the nuclear envelope has broken down (d). During this stage interphase centrosomes mature into mitotic centrosomes acquiring mitosis-associated centrosomal proteins including

NuMA that moves out of the nucleus to become a mitotic centrosomeassociated protein. The metaphase centrosome (e) becomes highly compacted to organize the metaphase spindle with microtubules attached to the kinetochores. Anaphase is the stage when centrosomal material becomes decompacted again (f) before reorganizing into interphase centrosomes that associate with the nuclei of the separating daughter cells (g). Centrosomes shaded yellow with centrioles and PCM displayed in black; nuclei shaded orange; microtubules displayed as black rods; chromosomes displayed in black. Modified from Sun and Schatten 2007 
clearly apparent at the G2 stage. The two centrosome complexes are held to each other throughout interphase and undergo disjunction prior to entry into mitosis (Mayor et al. 1999). Centrosome maturation takes place by acquiring mitotic centrosome proteins including Plk1 (Golsteyn et al. 1995), NuMA (Merdes et al. 1996) and others while interphase centrosome proteins such as C-Nap1 (Fry et al. 1998) or Nlp (Casenghi et al. 2003) are removed. Increased recruitment of $\gamma$-TuRC to the centrosome assures increased nucleation of microtubules for spindle formation. While centriole separation has been studied in great detail in recent years, our knowledge about centrosome separation is still incomplete and we do not yet fully understand how centrosomes are separated into two. Separation is complete when cells re-enter G1 with a single centrosome surrounding a pair of centrioles.

One of the well-studied essential mitotic centrosomeassociated proteins is NuMA. After nuclear envelope breakdown (NEB), NuMA becomes a most significant centrosome-associated protein (reviewed in Sun and Schatten 2006, 2007). NuMA does not associate with interphase centrosomes. It serves as nuclear matrix protein in the interphase nucleus and becomes dispersed into the cytoplasm during NEB, a process in which cyclin B plays a critical role. Cdk1/cyclin B dependent phosphorylation is important for translocation of NuMA from the nucleus into the cytoplasm (Saredi et al. 1997; and references therewithin) where it associates with microtubules using a dyneindynactin-mediated mechanism to be translocated along microtubules to the centrosome area. Next, to become a functional mitotic protein NuMA needs to be translocated from the cytoplasm to the mitotic centrosomes. In this highly regulated process microtubules and dynein-dynactin play crucial roles in transporting NuMA to the mitotic poles where it forms an insoluble crescent around centrosomes that tethers microtubules precisely into the bipolar configuration that forms the mitotic apparatus (Merdes and Cleveland 1998). NuMA is distributed to the separating centrosomes during early mitosis. It ensures minus-end binding and stabilization of microtubules on the centrosome area that faces chromosomes. NuMA facilitates crosslinking of spindle microtubules, aiding in the organization and stabilization of spindle poles from early mitosis to anaphase. To exit its mitotic functions and to relocate to the nucleus NuMA needs to be dissociated from the mitotic spindle poles through a process that requires cdc1/cyclin B (Gehmlich et al. 2004). Destruction of cyclin B promotes exit from mitosis, which starts at the mitotic poles and is linked to disassembling the mitotic centrosome complex. Failure of NuMA to relocate to the nucleus will result in cytoplasmic NuMA spots that organize abnormal microtubule formations (Gehmlich et al. 2004).

As nuclear matrix protein NuMA is involved in DNA replication and transcription. It displays distinct staining patterns in the nucleus (Merdes and Cleveland 1998; Zeng 2000; Gobert et al. 2001) and stains heavily in mitosis when using anti-NuMA antibodies (Saredi et al. 1997; Merdes et al. 2000; Gobert et al. 2001; Zhong et al. 2005; Liu et al. 2006). Inaccurate NuMA regulation and atypical NuMA distribution will result in abnormal mitosis as has been reported for cancer cells (Saunders et al. 2000).

Some of the important mitotic cell cycle regulators are concentrated at the centrosome and include Polo and Aurora A kinases (Barr and Gergely 2007), and cdc2/cyclin B kinase (Jackman et al. 2003). Some of these proteins bind to the anaphase promotion complex/cyclosome (APC/C). The activated APC/C ${ }^{\mathrm{Cdc} 20}$ degrades cyclin $\mathrm{B}$ and securin to allow cell cycle exit from mitosis (Kramer et al. 2000; Huang and Raff 1999; Wakefield et al. 2000).

Microtubule motor proteins are essential for the composition of a functional mitotic centrosome as many centrosome proteins are shuttled along microtubules to the centrosome core structure including pericentrin and NuMA. Pericentriolar satellites (or PCM-1 granules) may function as cargo vehicle for various proteins including ninein, centrin, and pericentrin (Dammermann and Merdes 2002). These PCM-1 granules move along microtubules in a dynein-dependent process (Kubo et al. 1999; Kubo and Tsukita 2003).

The microtubule motor proteins dynein and kinesin are crucial for transport of cargo along microtubules and balanced transport is important to maintain cellular homeostasis. In most cells, transport of cellular organelles such as mitochondria and vesicles along microtubules is mediated by the kinesin family of motor proteins to the plus end of microtubules and by cytoplasmic dyneins and its co-factor dynactin to the minus ends (reviewed by Welte 2004). Bidirectional transport of cell organelles and vesicles is also possible (Haggeness et al. 1978). Imbalanced transport can lead to pathologies related to centrosome and microtubule functions as well as to failures in organelle and vesicle distribution. Centrosome and microtubule pathologies are the result of disrupted transport. Disruption of transport is the cause or effect in a chain of signal transduction events; disruption depletes the resources of proteins and generates signals regulating transcription. Following disruption is a cascade of declines resulting in secondary pathologies. Microtubule-based transport processes are vital for cell functions and dysfunctional transport along microtubules has been implicated in cellular deterioration and disease such as Alzheimer's.

As is the case for transport toward the minus end transport of microtubules toward centrosomes dynein is involved in the mediation of transloction along microtubules to the plus ends towards the cell periphery. Dynein motors may be linked to actin or intermediate filaments as has been shown for neurons in which dynein and dynactin are responsible for translocation of microtubules from the 
centrosome in the cell body into the axon (Baas 1998; Ahmad et al. 1999). Myosin may play a role in connecting microtubules to actin filaments (Cao et al. 2003).

\section{Supernumerary centrosomes: role in genomic instability and cancer}

Boveri's visionary book on centrosome abnormalities in cancer had originally been translated from German into English as its significance and powerful implications had been recognized from the onset (Boveri 1914). This book has recently been re-edited, again because of its significance that continues to fascinate investigators in the centrosome field as well as others. The visionary research and intellectually remarkable interpretations implied one cell with abnormal centrosomes as the primordial tumor cell.

Boveri's observations of dispermic eggs developing multipolar mitoses and his brilliant thought process to imply supernumerary centrosomes in tumor has found enormous recognition during the past decade when several groups followed up on Boveri's initial findings and analyzed archived tumor tissues of various types. Since then multipolar mitoses have been identified in a large number of cancers as hallmarks of tumor tissue with direct implications in the causes for aneuploidy (Lingle and Salisbury 1999, 2000; Lingle et al. 1998; Pihan et al. 2003; Pihan and Doxsey 1999; Schatten et al. 1998a, b, 1999a, b, 2000a, b, c; Brinkley and Goepfert 1998; and others; reviewed in Goepfert and Brinkley 2004). Moreover, overexpression of specific centrosome proteins resulted in abnormal centrosome configurations and aneuploidy (Lingle et al. 2002; Katayama et al. 2003) confirming the important role of centrosomes in cancer development and progression. Increased centrosome number and volume, supernumerary centrioles, accumulation of increased PCM, and abnormal phosphorylation of centrosomes have all been associated with cancer cell centrosomes followed by loss of cell polarity (Lingle et al. 1998; Schatten et al. 2000c).

Deregulation of centrosome duplication and genes implicated in centrosome amplification are processes that lead to cascades of cell cycle-related abnormalities. The loss of p53 is associated with multiple cycles of centrosome duplication in one $\mathrm{S}$ phase resulting in multiple centrosome numbers (Pihan and Doxsey 1999). P53 might play a role in the block to reduplication in synchrony with the DNA cycle. Viral oncoproteins that inactivate p53 also result in cells with supernumerary centrosomes as has been shown for the papilloma virus (reviewed in Münger and Duensing 2004). However, different investigators have challenged that loss of p53 directly affects centrosome duplication (Meraldi et al. 2002) and attribute centrosome abnormalities to missing checkpoint functions after loss of p53.
The breast cancer suppressor gene BRCA1 may also play a role in deregulation of centrosome duplication as targeted deletion of BRCA1 exon11 leads to centrosome amplification (Xu et al. 1999). However, the mechanism by which BRCA1 affects centrosome duplication remains to be fully investigated. BRCA1 plays a role in $\mathrm{G} 2 / \mathrm{M}$ checkpoint functions which may result in loss of the block to centrosome reduplication.

Aurora kinases play central roles in the mitotic process and cell division and Aurora A has been implicated in centrosome amplification in breast cancer. Aurora A localizes to centrosomes and overexpression of Aurora A causes multipolar mitotic spindles and is implicated in early development of mammary tumors.

Oncogenic insults may result in a high number of mutation rates in cells predispositioned to tumor and the mutation rate increases in cells that have reached replicative senescence. In contrast, cervical carcinogenesis has strongly been associated with infections by high-risk human papillomavirus (HPVs). It has been suggested that the HPV E7 oncoprotein may induce primary centrosome duplication errors and act as mitotic mutator (reviewed in Münger and Duensing 2004). As with other cancers, abnormal multipolar mitoses resulting from supernumerary centrosomes have clearly been associated with HPV-associated lesions and centrosome abnormalities are already detected in early stages of tumor development. Studies have shown that uncoupling of the cell division cycle from the centrosome cycle subverts centrosome homeostasis (Duensing et al. 2000).

An emerging field in centrosome research is their role in aging. Supernumerary centrosomes are thought to be associated with aging and have been shown in senescing cells (Schatten et al. 1999a). Many of the cell cycle regulators that play a role at the transition from $\mathrm{G} 2$ to M phases are downregulated in aging cells (Ly et al. 2000), which is the most significant phase for reorganizations of microtubules and centrosomes. As mentioned above, centrosomes undergo major changes in phosphorylation at the $\mathrm{G} 2 / \mathrm{M}$ transition and it has been shown that centrosomes in aging cells have lower activity in centrosome-associated protein kinases (Cande 1990; Huang 1990). Plk has been identified as one of the gene products that are down-regulated in aging cells (Ly et al. 2000), which will have significant consequences for centrosome and microtubule organization. This is important considering that many diseases of aging involve inaccurate microtubule organization coupled with transport dysfunctions.

\section{Centrosome-independent pathways and non-centrosomal microtubule arrays}

Typical centrosomes are absent in most plant cells and centrosome material without centrioles compose the meiotic 
spindle in animal oocyte cells. Somatic cells also can assemble bipolar spindles in the absence of typical centrosomes (Meraldi and Nigg 2002; Manandhar et al. 2005). In animal cells, microsurgery to remove the centrosome from transformed mouse fibroblast cells (L929 cells) resulted in reorganization of microtubules without a centrosome but absence of a mitotic spindle and cell cycle progression arrest implying that the centrosome is important for cell cycle progression. Although the centrosome is vital for animal cells and there are no viable mutants in animal cells that lack centrosomes there are centrosome-independent pathways that have recently been explored by destroying centrosomes in situ with focused pulses of high-energy (laser) light, termed the "ablative photo-decomposition" approach (reviewed in Khodjakov and Rieder 2004). These studies used Green Fluorescent Protein (GFP) fusion for detection of centrosomes for precise centrosome targeting and to follow the extent of centrosome destruction in live cells. These studies showed that some acentrosomal spindle formation is possible when centrosomes are destroyed.

In parthenogenetic human, rhesus, and bovine embryos a bipolar spindle is formed at the time of first mitosis without apparent $\gamma$-tubulin and pericentrin foci at the spindle poles which argues that mitotic spindles can self-assemble without functional MTOCs. Acentrosomal meiotic and mitotic spindles have been described (Lee et al. 2000; Megraw et al. 2001; Bonaccorsi et al. 2000; Khodjakov et al. 2000; Khodjakov and Rieder 2001; Raff 2001). It is not entirely clear how the spindle poles are formed but microtubule motor activities have been implicated in this process (Walczak et al. 1998).

Release of entire microtubules from the centrosome complex has been well documented as the main mechanism to produce non-centrosomal, free microtubules in neurons (Ahmad et al. 1999). The microtubule-severing protein katanin has been implicated in this process (Ahmad et al. 1999; Baas 1999; McNally and Vale 1993; McNally et al. 2000). Katanin may also play a role in M-phase severing processes at the spindle poles in mammalian cells when spindle pole microtubules become depolymerized (McNally et al. 1996; McNally and Thomas 1998). Katanin also plays a role in severing of axonemal microtubules (Lohret et al. 1998) and katanin-like proteins have been identified in plants (Burk et al. 2001).

Non-centrosomal microtubule arrays have been described for polarized epithelial cells (reviewed by Morgensen 2004) to serve various specialized functions of differentiated cells. In these cells centrosomes are present but organize fewer microtubules while most of the cellular microtubules are non-centrosomal and the minus ends are localized toward the plasma membrane without $\gamma$-tubulin anchorage. Such organization is seen in rat Sertoli cells (Vogl et al. 1995). Other examples of non-centrosomal microtubules with significant cellular functions are found in the organ of Corti in the inner ear, and during vertebrate myogenesis. The microtubule minus end-anchoring protein ninein is localized to the noncentrosomal microtubule minus-end sites in MDCK polarized epithelial cells while $\gamma$-tubulin or pericentrin are absent.

Microtubule-associated proteins (MAPs) at the minus ends may play a role in minus end-capping of microtubules preventing their depolymerization. Plus-end capping involves Rho GTPases and the downstream effector mDia (mouse diaphanous-related formins) (Gundersen 2002; Palazzo et al. 2001). Other plus-end capping candidates are CLIP-170, EB1, dynein/dynactin, and APC (adenomatis polyposis coli) protein (reviewed in Mogensen 2004). It is thought that these non-centrosomal microtubules originate from centrosomes. Dynactin also localizes to the non-centrosomal microtubule minus-end sites in MDCK polarized epithelial cells in further support for anchorage sites at the cell apex. A microtubule release and capture mechanism has been implicated in the generation of non-centrosomal apico-basal microtubule formations in polarized epithelial cells. The non-centrosomal microtubule organization provides support for the idea that two functionally distinct microtubule minus-end-associated complexes are independent from each other and comprise the nucleating complex and the anchoring complex. The role of ninein in microtubule anchorage at the centrosomal PCM has been reported by Mogensen et al. (2000). The minus end microtubule anchoring capabilities by ninein have been demonstrated by overexpression of ninein causing an increase of microtubule anchorage and decrease in microtubule release. The loss of microtubule radial organization has been demonstrated by using either anti-ninein antibodies or RNAi depletion of ninein (Dammermann and Merdes 2002).

\section{Centrosome abnormalities and mitotic cell death}

Alterations in centrosome organization and function are associated with cellular stress and may be part of the mitotic catastrophe response characteristic for programmed mitotic cell death. Centrosome structure and function are directly affected by chaotropic agents such as formamide (Schatten et al. 2000d) and in response to heat shock and DNA damage. While mild heatshock treatment triggers repair mechanisms and centrosome thermotolerance severe heat shock leads to cell death by a mitotic catastrophe mechanism. Formamide induces the formation of multipolar spindles perhaps as a result of centrosomal protein denaturation (Schatten et al. 2000d). Tripolar and fractionated centrosomes after treatment of cells with formamide are shown in Fig. 6a and b, respectively. The effects of heat shock and other environmental stresses have been studied in various cell systems that all displayed centrosome altera- 


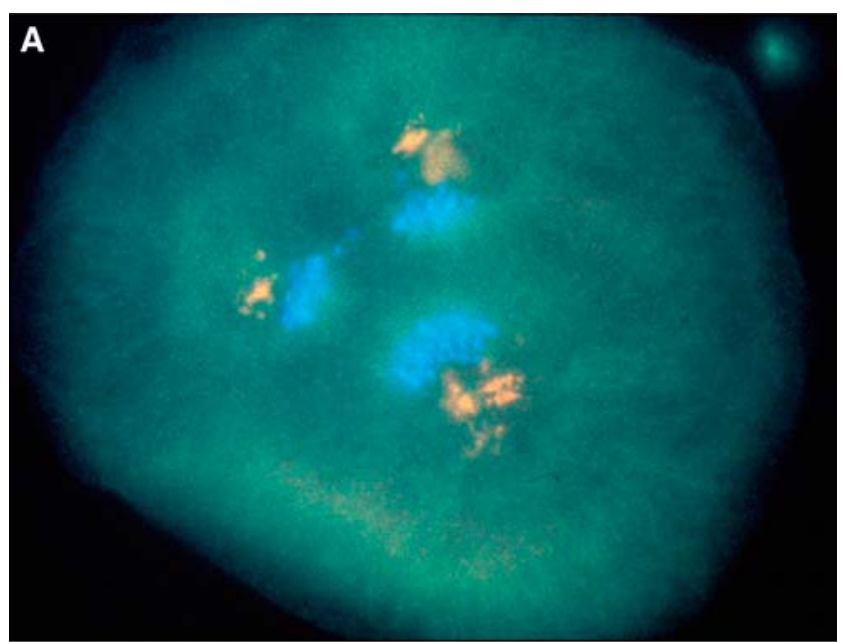

B

$25 \mu \mathrm{m}$

Fig. 6 The chaotropic agent formamide causes centrosomal damage and results in tripolar (a) or multiple (b) centrosomal foci as shown here in an example using sea urchin eggs as model system. Centrosomes labeled red (a) or green (b). Microtubules in $\mathbf{b}$ labeled red $\mathbf{a}=$ modified from Schatten et al. 2000d

tions. Hsp70 was localized to centrosomes in HeLa cells (Rattner 1991); Nakahata et al. (2002) reported centrosomal dysfunction and non-apoptotic mitotic catastrophe in human tumor cells which has also been reported for cells exposed to radiation (reviewed in Sato et al. 2004). Some of the causes for mitotic catastrophe are related to checkpoint or DNA repair failures which is thought to be a genetically programmed response to genotoxic stress leading to centrosome inactivation (Sibon et al. 2000). Loss of $\gamma$-tubulin, loss of pericentrin and multipolar spindles as well as additional PCM foci and structural alterations are some of the characteristics associated with heat shock (Vidair et al. 1995, 1996, 1993; Barrau et al. 1978; Knox et al. 1991; Debec et al. 1990; Marcaillou et al. 1993; Debec and Marcaillou 1997). Cells with mitotic catastrophe and multipolar spindles are eliminated from a cell population by a process resulting in cell death which has been reported for mammalian somatic cells as well as for Drosophila cells in culture
(Schatten et al. 1999a). This process is used in addition to apoptosis to eliminate cells with dysfunctional mitotic cells from a normal cell population. It has also been shown to account for causes of embryo abnormalities after somatic cell nuclear transfer (SCNT) (reviewed in Schatten et al. 2005; Zhong et al. 2007). Such cells undergoing mitotic cell death are negative for TUNEL staining and isolated DNA is not characterized by laddering that is typical for apoptosis (Roninson et al. 2001; Nabha et al. 2002). Apoptotic inhibitors are not effective in these cells and apoptotic bodies are not formed while fragmentation of centrosomes appears characteristic for mitotic cell death.

Ionizing radiation is well known to induce aberrations in centrosome number in tumor cell lines but the underlying causes are not well understood (Sato et al. 1983, 2000a, b). As discussed above for heat shock damage the DNA checkpoint pathways may play a role in radiation-induced centrosome aberrations or it may directly affect centrosome structure. Mitotic cell death is seen in most cell types after ionizing radiation while apoptosis is primarily seen in lymphoma and leukemia cells. Exposure to gamma-irradiation at a single dose of $10 \mathrm{~Gy}$ resulted in increased numbers of centrosomes with varied abnormalities and cell fractionation (reviewed in Sato et al. 2004). Mitotic cell death after mitotic catastrophe is also caused by other chemotherapeutic agents such as doxorubicin, cisplatin, bleomycin, and taxol (Roninson et al. 2001; Schatten et al. 2000a, b). The causes for centrosome number increases after irradiation are not clear but loss of cell cycle regulators such as p53 and its downstream targets p21 and Gadd45 have been implicated in supernumerary centrosomes (Fukasawa et al. 1996; Hollander et al. 1999; Mantel et al. 1999; Carroll et al. 1999). Dissociation of centrosome cycles from DNA cycles may be among the causes for centrosome aberrations and multipolar spindle formations after irradiation. Aberrant hypermethylation has recently been implicated in inactivation of checkpoint genes that may influence cell cycledependent centrosome abnormalities as reported for pancreatic cancer (Ohki et al. 2000; Sato et al. 2003).

Environmental stress can result in the formation of aggresomes which are oftentimes localized close to centrosomes and are thought to be the result of misfolded proteins (Ellgaard et al. 1999; Johnston et al. 1998; Wojcik and DeMartino 2003; Kopito 2000; Roth et al. 2008). Some of the aggresomes contain $\gamma$-tubulin and are associated with disease or neurodegenerative disorders such as Parkinson's disease and dementia (McNaught et al. 2002).

\section{Centrosomes in reproduction including fertilization and somatic cell nuclear transfer (SCNT)}

Boveri's brilliant discoveries on centrosomes primarily came from his studies on centrosomes during fertilization 
and cell division in sea urchin eggs (Boveri 1901), which resulted in a wealth of profound information on the important contribution of sperm centrosomes for successful fertilization. His work on reproduction also resulted in the remarkable insights that supernumerary centrosomes are at the core of malignant tumors (Boveri 1914) which was based on his observations that dispermic eggs (eggs fertilized with two sperm) developed multipolar mitotic poles. An example of a dispermic sea urchin egg is seen in Fig. 7. Boveri had recognized that sperm contribute the dominant centrosomal material that was detected by staining with iron hematoxylin and could be traced throughout cell division and development. In more recent years, staining of centrosomes with immunological probes confirmed that in most animal species except for the mouse (Schatten et al. 1986, 1987) dominant centrosomal material is contributed by sperm (reviewed in Manandhar et al. 2005; Sun and Schatten 2006, 2007) and biparental centrosome contributions to the zygote are typical for most species. More detailed studies using specific immunofluorescent probes to specific centrosome proteins provided additional insights into centrosomal contributions during gametogenesis and fertilization (reviewed by Manandhar et al. 2005). These studies showed that the sperm retains its proximal centriole while losing most of the PCM. The oocyte, on the other hand degenerates centrioles while retaining centrosomal proteins. The sperm's proximal centriole recruits egg proteins shortly after sperm incorporation including $\gamma$-tubulin, centrin, pericentrin, and NuMA to the sperm centriolar complex. The recruitment of maternal $\gamma$-tubulin to the sperm's centrosomal $\gamma$-tubulin results in a significant accu-

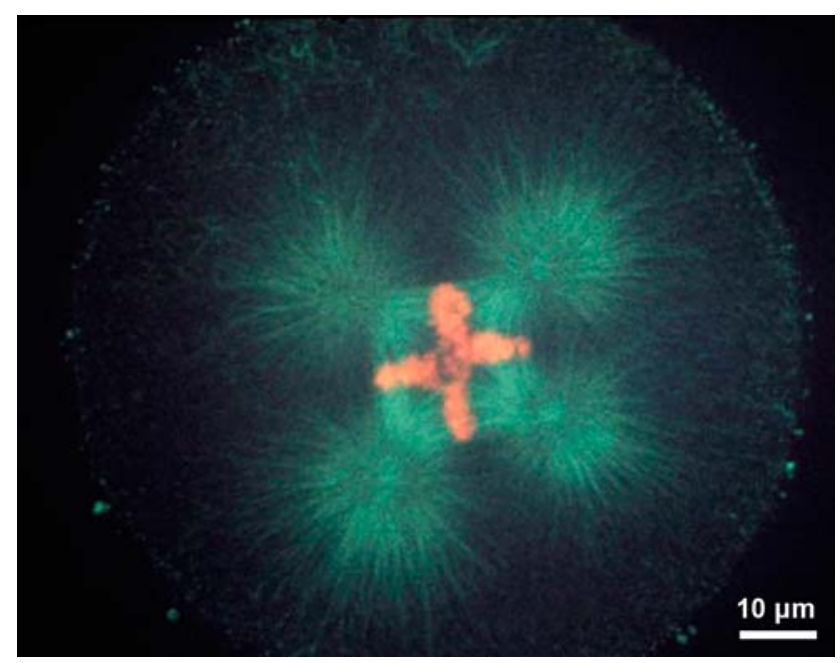

Fig. 7 A tetrapolar spindle displaying microtubules (green) and chromosomes (red) as a result of dispermy in a sea urchin egg. Such results on dispermic eggs had stimulated Boveri to propose that centrosome abnormalities are at the core of malignant tumors. Image produced in collaboration at the Integrated Microscopy Resource at the University of Wisconsin mulation of $\gamma$-tubulin. The blended centrosome after fertilization also contains centrin from both sperm and egg. The zygotic centrosome that is closely associated with the decondensing male pronucleus then organizes a radial aster that grows toward the female pronucleus. The centriolecentrosome complex duplicates during the pronuclear stage. A zygote aster forms around the appositioned (or fused) male and female pronuclei (zygote nucleus) and centrosomes separate to form the bipolar mitotic apparatus in preparation for cell division (reviewed in Sun and Schatten 2006, 2007). Dysfunctional sperm centrosomes, dysfunctional zygote centrosomes, and polyspermy have been implicated in causes for male-derived infertility (reviewed in Schatten 1994) while aging of oocyte centrosomes is among the major causes for infertility in older women (Battaglia et al. 1996) as dysfunctional centrosomes are implied in the causes for aneuploidy. It is estimated that the rates of aneuploidy in preimplantation human embryos is as high as 52-61\% (Munne and Cohen 1998).

\section{Centrosome remodeling after nuclear transfer:}

communication between embryonic and somatic cells

Cloning of animals by somatic cell nuclear transfer (SCNT) involves cellular communication of embryonic cells with somatic cell nuclei and somatic cell centrosomes from donor cells. In recent years, cloning of animals by SCNT has opened up new avenues to produce genetically modified species with higher nutritional value or improved traits that are useful in agriculture. Genetically modified pigs have been produced as models for human disease and for various other biomedical applications (reviewed in Prather 2000, 2007; Schatten et al. 2005). However, one of the major difficulties to overcome in cloning is the low cloning efficiency that ranges from 1 to $5 \%$ in different animals. Centrosomal dysfunctions have been identified as possible causes for low cloning efficiencies in several species including the pig (Zhong et al. 2007) and rhesus monkeys (Simerly et al. 2003) and centrosomal dysfunctions may also play a role in developmental abnormalities that are frequently associated with cloning.

SCNT involves transferring a somatic cell nucleus with known genetic value into an enucleated oocyte from a different animal followed by electrical activation. Subsequently, SCNT requires communication of enucleated oocytes with the donor cell nucleus and its associated centrosome. The complex molecular regulation and functions of centrosomes in reproductive cells are complicated by the fact that somatic cell centrosomes need to be remodeled by the enucleated oocyte (reviewed in Sun and Schatten 2007), which is crucially important as the donor cell's centrosome is required to perform all functions that are normally fulfilled by the blended sperm and egg centrosomal material. 
Under these conditions, the enucleated oocyte's cytoplasmic regulatory machinery is required to regulate the donor cell centrosome for embryo-specific functions. Centrosome dysfunctions may occur as the oocyte's cell cycle regulation systems are different from those used by somatic cells. Indeed, multipolar mitoses resulting from supernumerary centrosomes have been reported in reconstructed pig oocytes (Zhong et al. 2007) which may be among the underlying causes for decreased cell numbers as a result of increased mitotic cell death.

While blending of sperm and egg centrosomal material into a functional centrosome after fertilization is necessary for embryo-specific functions, it is not known whether the donor cell centrosome also attracts centrosomal components from the oocyte or whether the somatic cell centrosome is able to nucleate and organize microtubules for oocyte-specific functions without oocyte centrosomal components. Aberrant composition of centrosome proteins will result in abnormal microtubule organizations as has been discussed for cancer cells. As the donor cell centrosome contains $\gamma$-tubulin and $\gamma$-TuRC it is not clear whether it attracts additional $\gamma$-tubulin from the oocyte as is the case for sperm centrosomes. Analysis of cancer cell centrosomes revealed increased $\gamma$-tubulin associated with centrosomes resulting in more than the normal number of microtubules leading to aneuploidy (Lingle et al. 1998; Schatten et al. $2000 \mathrm{a}, \mathrm{b})$. Increased accumulation of microtubules in the reconstructed egg may also play a role in centrosome dysfunctions resulting in abnormal microtubule organization and aneuploidy (Zhong et al. 2007; Martin et al. 2007). The composition of the centrosome in reconstructed oocytes is not known and needs further investigation to determine whether oocyte-stored centrosome proteins are recruited to the donor cell centrosome.

SCNT also challenges nucleo-cytoplasmic interactions as several centrosome proteins such as NuMA are localized in the nucleus, adding further complexities to centrosome remodeling. The oocyte's regulatory systems have to communicate with the donor cell's nuclear and centrosomal material as many of the cell-cycle-dependent centrosome proteins are of nuclear origin and depend on nucleo-cytoplasmic interactions for cell cycle-specific and developmentally regulated functions. Such functions include governing microtubule-mediated translocation of mitochondria for spatio-temporal requirements for ATP, translocation of macromolecular complexes, vesicles that may contain enzymes, and translocation of transient centrosome-associated proteins that are needed for molecular centrosome restructuring to perform cell cycle-specific centrosome functions. We do not yet have information on the role of cyclin B in centrosome remodeling in reconstructed embryos which will be important information to obtain as cyclin B is one of the major regulators of centro- somes and is crucial for centrosome maturation and for cell cycle-dependent molecular centrosome dynamics. Cyclin B is a critical regular of NuMA association with centrosomes and its release from spindle poles during exit from mitosis (Saredi et al. 1997; Merdes and Cleveland 1998; Gehmlich et al. 2004). In contrast to mammalian somatic cells in which cyclin B synthesis increases during G2 and M mainly as the result of cyclin B gene transcription increase, in embryonic cells cyclin B synthesis is constant throughout the cell cycle and cyclin B accumulation is the result of decrease in its degradation rate.

Taken together, studies of centrosomes in reconstructed embryos will provide new avenues to obtain information on centrosomal regulation by cytoplasmic factors.

\section{Concluding remarks and future directions}

Renewed interest in centrosome research started about 25 years ago when it was shown that certain autoimmune sera from CREST patients would reliably label centrosome material in animal cells. Since then, rapid progress has been made to identify specific centrosome proteins and determine their functions, which led to renewed appreciation of the enormous significance that centrosomes carry as cellular organelles and as major platform for cellular regulation. Centrosome dysfunctions have been linked to various human genetic diseases (reviewed in Badano et al. 2005) and centrosomes can directly be affected by environmental and genotoxic stresses. Adverse effects on centrosomes will result in multiple cascades of cellular dysfunctions as centrosomes regulate distribution of cellular organelles including mitochondria which are the major source for ATP production and depend on microtubules for distribution to their cell cycle-specific functional destinations. Based on these new insights it is easy to understand that centrosomes are linked to many diseases in which transport along microtubules is impaired which includes Alzheimer's and several neurological diseases in which extensive trafficking along microtubules takes place. This area of research with a new focus on centrosomes is just at the beginning.

The entire field of aging research is open to investigations of centrosomes in senescing cells. Our previous studies on Drosophila cells in culture have linked multipolar mitoses to cellular senescence (Schatten et al. 1999a) and further studies are needed to explore centrosome regulation in aging cells. Other new areas of research include the effects of environmental stresses on centrosomes and manipulation and exploitation of centrosomes and the associated microtubule cytoskeleton by pathogens which has been explored for Toxoplasma parasites (Coppens et al. 2006) and has been reviewed by Scaplehorn and Way (2004) in a recent book dedicated to various aspects of centrosome research (Nigg 2004). Taken together, we are in 
the middle but also at the beginning of new appreciation for the centrosome as key organelle and as main station for directing and regulating cellular processes through its microtubule highway system and further research will undoubtedly result in uncovering and perhaps also repairing pathologies related to centrosome dysfunctions.

Acknowledgments The present article remembers the late Daniel Mazia for his inspiration, friendship, and dissemination of an everexpanding research area in cellular and molecular biology as well as in microbiology. Daniel Mazia's passionate lecture on centrosomes during a 1984 UNESCO-ICRO course in Palermo/Italy along with numerous subsequent fascinating discussions on centrosomes first inspired the author's research focus on centrosomes. Appreciation is extended to Donald Connor for excellent help with the schematic diagrams and assembly of images. Figure 4E was kindly supplied by Dr. Mika Katayama resulting from a collaborative project (Katayama et al. 2006). Figure 4 a, c, d were kindly provided by Dr. Zhisheng Zhong resulting from a collaborative project (Zhong et al. 2007). Figure 7 had been produced in collaborations at the University of Wisconsin-Madison and the results using formamide had been obtained in collaboration with the late Daniel Mazia.

\section{References}

Ahmad FJ, Yu W, McNally FJ, Baas PW (1999) An essential role for katanin in severing microtubules in the neuron. J Cell Biol 145:305-315

Andersen JS, Wilkinson CJ, Mayor T, Mortensen P, Nigg EA, Mann M (2003) Proteomic characterization of the human centrosome by protein correlation profiling. Nature 426:570-574

Baas PW (1998) The role of motor proteins in establishing the microtubule arrays of axons and dendrites. J Chem Neuroanat 14:175-180

Baas PW (1999) Microtubules and neuronal polarity: lessons from mitosis. Neuron 22:23-31

Badano JL, Teslovich TM, Katsanis N (2005) The centrosome in human genetic disease. Nat Rev Genet 6:194-205

Bailly E, Dorée M, Nurse P, Bornens M (1989) P34cdc2 is located in both nucleus and cytoplasm; part is centrosomally associated at G2/M and enters vesicles at anaphase. EMBO J 8:3985-3995

Balczon R, Bao L, Zimmer WE, Brown K, Zinkowski RP, Brinkley BR (1995) Dissociation of centrosome replication events from DNA synthesis and mitotic division in hydroxyurea-arrested Chinese hamster ovary cells. J Cell Biol 130:105-115

Barr AR, Gergely F (2007) Aurora A: the maker and breakerof spindle poles. J Cell Sci 120:2987-2996

Barrau MD, Blackburn GR, Dewey WC (1978) Effects of heat on the centrosomes of Chinese hamster ovary cells. Cancer Res 38:2290-2294

Battaglia DE, Klein NA, Soules MR (1996) Changes in centrosomal domains during meiotic maturation in the human oocyte. Mol Hum Reprod 2(11):845-851

Bonaccorsi S, Giansanti MG, Gatti M (2000) Spindle assembly in Drosophila neuroblasts and ganglion mother cells. Nat Cell Biol 2:54-56

Bornens M (2002) Centrosome composition and microtubule anchoring mechanisms. Curr Opion Cell Biol 14:25-34

Boveri T (1901) Zellen-Studien: Über die Natur der Centrosomen. Jena. Germany: Fisher Z Med Naturw 28:1-220

Boveri T (1914) Zur Frage der Entstehung maligner Tumoren. G. Fisher, Jena, Germany

Brinkley BR, Goepfert TM (1998) Supernumerary centrosomes and cancer: Boveri's hypothesis resurrected. Cell Motil Cytoskeleton 41:281-288
Burk DH, Liu B, Zhong R, Morrison WH, Ye ZH (2001) A kataninlike protein regulates normal cell wall biosynthesis and cell elongation. Plant Cell 13:807-827

Calarco-Gillam PC, Siebert MC, Hubble R, Mitchison T, Kirschner M (1983) Centrosome development in early mouse embryos as defined by an autoantibody against pericentriolar material. Cell 35(3 Pt 2):621-629

Canaday J, Stoppin-Mellet V, Mutterer J, Lambert A, Schnit A-C (2000) Higher plant cells: gamma-tubulin and microtubule nucleation in the absence of centrosomes. Microsc Res Tech 49:487495

Cande Z (1990) Centrosomes: composition and reproduction. Curr Opin Cell Biol 2:301-305

Cao K, Nakajima R, Meyer HH, Zheng Y (2003) The AAA-ATPase Cdc48/p97 regulates spindle disassembly at the end of mitosis. Cell 115:355-367

Carroll E, Okuda M, Horn HF, Biddinger P, Stambrook PJ, Gleich LL, Li YQ, Tarapore P, Fukasawa K (1999) Centrosome hyperamplification in human cancer: chromosome instability induced by p53 mutation and/or Mdm2 overexpression. Oncogene 18:1935-1944

Casenghi M, Meraldi P, Weinhart U, Duncan PI, Korner R, Nigg EA (2003) Polo-like kinase 1 regulates Nlp, a centrosome protein involved in microtubule nucleation. Dev Cell 5:113-125

Chan J, Calder GM, Doonan JH, Lloyd CW (2003) EB1 reveals mobile microtubule nucleation sites in Arabidopsis. Nat Cell Biol 5:967971

Coppens I, Dunn JD, Romano JD, Pypaert M, Zhang H, Boothroyd JC (2006) Toxoplasma gondii sequesters lysosomes from mammalian hosts in the vacuolar space. Cell 125:261-274

Dammermann A, Merdes A (2002) Assembly of centrosomal proteins and microtubule organization depends on PCM-1. J Cell Biol 159:255-266

Daunderer CC, Schliwa MM, Gräf RR (1999) Dictyostelium discoideum: a promising centrosome model system. Biol Cell 91:313-320

Debec A, Marcaillou C (1997) Structural alterations of the mitotic apparatus induced by the heat shock response in Drosophila cells. Biol Cell 89:67-78

Debec A, Courgeon A, Maingourd M, Maisonhaute C (1990) The response of the centrosome to heat shock and related stresses in a Drosophila cell line. J Cell Sci 96:403-412

Dictenberg J, Zimmerman W, Sparks C, Young A, Vidair C, Zheng Y, Carrington W, Fay F, Doxsey SJ (1998) Pericentrin and gamma tubulin form a protein complex and are organized into a novel lattice at the centrosome. J Cell Biol 141:163-174

Donaldson MM, Tavares AAM, Hagan IM, Nigg EA, Glover DM (2001) The mitotic roles of polo-like kinase. J Cell Sci 114:23572358

Doxsey SJ, Stein P, Evans L, Calarco P, Kirschner M (1994) Pericentrin, a highly conserved protein of centrosomes involved in microtubule organization. Cell 76:639-650

Duensing S, Lee LY, Duensing A, Basile J, Piboonniyom S, Gonzalez S, Crum CP, Munger K (2000) The human papillomavirus type 16 E6 and E7 oncoproteins cooperate to induce mitotic defects and genomic instability by uncoupling centrosome duplication from the cell division cycle. Proc Natl Acad Sci USA 97:10002-10007

Ellgaard L, Molinari M, Helenius A (1999) Setting the standards: quality control in the secretory pathway. Science $286: 1882-1888$

Fan H-Y, Tong C, Teng C-B, Lian L, Li S-W, Yang Z-M, Chen D-Y, Schatten H, Sun Q-Y (2003) Characterization of polo-like kinase1 in rat oocytes and early embryos implies its functional roles in the regulation of meiotic maturation, fertilization and cleavage. Mol Reprod Dev 65:318-329

Fenton B, Glover DM (1993) A conserved mitotic kinase active at late anaphase-telophase in syncytial Drosophila embryos. Nature 363:637-640 
Flemming W (1875) Studien über die Entwicklungsgeschichte der Najaden. Sitzungsber Akad Wissensch Wien 71:81-147

Flemming W (1891) Verhandlungen der anatomischen Gesellschaft, Jahrg. 6, München (found as item $60 \mathrm{vol}$ II in Collected Papers of Walther Flemming in M.B.L. Library, reprint collection)

Flory MR, Davis TN (2003) The centrosomal proteins pericentrin and kendrin are encoded by alternatively spliced products of one gene. Genomics 82:401-405

Freed E, Lacey KR, Huie P, Lyapina SA, Deshaies RJ, Stearns T, Jackson PK (1999) Components of an SCF ubiquitin ligase localize to the centrosome and regulate the centrosome duplication cycle. Genes Dev 13:2242-2257

Fry AM (2002) The Nek2 protein kinase: a novel regulator of centrosome structure. Oncogene 21:6184-6194

Fry AM, Hames RS (2004) The role of the centrosome in cell cycle progression. In: Nigg E (ed) Centrosomes in development and disease. Wiley-VCA Verlag GmbH \& CoKGaG, Weinheim, pp 143-166

Fry AM, Mayor T, Meraldi P, Stierhof YD, Tanaka K, Nigg EA (1998) C-Nap1, a novel centrosomal coiled-coil protein and candidate substrate of the cell cycle-regulated protein kinase Nek2. J Cell Biol 141:1563-1574

Fukasawa K, Choi T, Kuriyama R, Rulong S, Vande Woude GF (1996) Abnormal centrosome amplification in the absence of p53. Science 271:1744-1747

Gard DL, Hafezi S, Zhang T, Doxsey SJ (1990) Centrosome duplication continues in cycloheximide-treated Xenopus blastulae in the absence of a detectable cell cycle. J Cell Biol 110:2033-2042

Gehmlich K, Haren L, Merdes A (2004) Cyclin B degradation leads to NuMA release from dynein/dynactin and from spindle poles. EMBO Rep 5:97-103

Gillingham AK, Munro S (2000) The PACT domain, a conserved centrosomal targeting motif in the coiled-coil proteins AKAP450 and pericentrin. EMBO Rep 1:524-529

Gobert GN, Hueser CN, Curran E, Sun Q-Y, Glinsky VV, Welshons W, Eisenstark A, Schatten H (2001) Immunolocalization of NuMA and phosphorylated proteins during the cell cycle in human breast and prostate cancer cells as analyzed by immunofluorescence and postembedding immunoelectron microscopy. Histochem Cell Biol 115:381-395

Goepfert TM, Brinkley WR (2004) Centrosome anomalities in cancer: from early observations to animal models. In: Nigg E (ed) Centrosomes in development and disease. Wiley-VCA Verlag GmbH \& CoKGaG, Weinheim, pp 323-336

Golsteyn RM, Mundt KE, Fry AM, Nigg EA (1995) Cell cycle regulation of the activity and subcellular localization of Plk1, a human protein kinase implicated in mitotic spindle function. J Cell Biol 129:1617-1628

Gstaiger M, Marti A, Krek W (1999) Association of human SCF(SKP2) subunit p19(SKP1) with interphase centrosomes and mitotic spindle poles. Exp Cell Res 247:554-562

Gundersen GG (2002) Evolutionary conservation of microtubule-capture mechanisms. Nat Rev Mol Cell Biol 3:296-304

Gunawardane RN, Martin OC, Cao K, Zhang L, Dej K, Iwamatu A, Zheng Y (2000) Characterization and reconstitution of Drosophila $\gamma$-tubulin ring complex subunits. J Cell Biol 151:1513-1523

Gunawardane RN, Martin OC, Zheng Y (2003) Characterization of a new $\gamma$-TuRC subunits with WD repeats. Mol Biol Cell 14:1017-1026

Haggeness MH, Simon M, Singer SJ (1978) Association of mitochondria with microtubules in cultured cells. Proc Natl Acad Sci U S A $75: 3863-3866$

Hannak E, Oegema K, Kirkham M, Gonczy P, Habermann B, Hyman AA (2002) The kinetically dominant assembly pathway for centrosomal asters in Caenorhabditis elegans is \{gamma\}-tubulin dependent. J Cell Biol 157:591-602
Hinchcliffe EH, Li C, Thompson EA, Maller J, Sluder G (1999) Requirement of Cdk2-cyclinE activity for repeated centrosomereproduction in Xenopus egg extracts. Science 283:851-854

Hollander MC, Sheik MS, Bulavin DV, Lundgren K, Augeri-Henmueller L, Shehee R, Molinaro TA, Kim KE, Tolosa E, Ashwell JD, Rodenber MP, Zhan Q, Fernandez-Salguero PM, Morgan WF, Deng CX, Fornace AJ Jr (1999) Genomic instability in Gadd45adeficient mice. Nat Genet 23:176-184

Huang B (1990) Genetics and biochemistry of centrosomes and spindle poles. Curr Opin Cell Biol 2:28-32

Huang J, Raff JW (1999) The disappearance of cyclin B at the end of mitosis is regulated spatially in Drosophila cells. EMBO J 18:2184-2195

Jackman M, Lindon C, Nigg E, Pines J (2003) Active cyclin B1-Cdk1 first appears on centrosomes in prophase. Nat Cell Biol 5:143148

Johnston JA, Ward CL, Kopito RR (1998) Aggresomes: a cellular response to misfolded proteins. J Cell Biol 143:1883-1898

Joshi HC, Palacios MJ, McNamara L, Cleveland DW (1992) $\gamma$-Tubulin is a centrosomal protein required for cell cycle-dependent microtubule nucleation. Nature 356:8083

Jurczyk A, Gromley A, Redick S et al (2004) Pericentrin forms a complex with intraflagellar transport proteins and polycystin-2 and is required for primary cilia assembly. J Cell Biol 166(5):637-643

Katayama H, Brinkley WR, Sen S (2003) The Aurora kinases: role in cell transformation and tumorigenesis. Cancer Metastasis Rev 22:451-464

Katayama M, Zhong Z-S, Lai L, Sutovsky P, Prather RS, Schatten H (2006) Mitochondria distribution and microtubule organization in fertilized and cloned porcine embryos: implications for developmental potential. Dev Biol 299:206-220

Kawaguchi S, Zheng Y (2004) Characterization of a Drosophila centrosome protein $\mathrm{CP} 309$ that shares homology with Kendrin and CG-NAP. Mol Biol Cell 15:37-45

Keryer G, Di Fiore B, Celati C, Lechtreck KF, Mogensen M, Delouvee A, Lavia P, Bornens M, Tassin AM (2003) Part of Ran is associated with AKAP450 at the centrosome: involvement in microtubule-organizing activity. Mol Biol Cell 14:4260-4271

Khodjakov A, Rieder CL (1999) The sudden recruitment of gammatubulin to the centrosome at the onset of mitosis and its dynamic exchange throughout the cell cycle, do not require microtubules. J Cell Biol 146:585-596

Khodjakov A, Rieder CL (2001) Centrosomes enhance the fidelity of cytokinesis in vertebrates and are required for cell cycle progression. J Cell Biol 153:237-242

Khodjakov A, Rieder CL (2004) A synergy of technologies: using Green Fluorescent Protein tagging and laser microsurgery to study centrosome function and duplication in vertebrates. In: Nigg E (ed) Centrosomes in development and disease. WileyVCA Verlag GmbH \& CoKGaG, Weinheim, pp 191-210

Khodjakov A, Cole RW, Oakley BR, Rieder CL (2000) Centrosomeindependent mitotic spindle formation in vertebrates. Curr Biol 10:59-67

Knop M, Pereira G, Schiebel E (1999) Microtubule organization by the budding yeast spindle pole body. Biol Cell 91:291-304

Knox JD, Mitchell RE, Brown DL (1991) Effects of hyperthermia on microtubule organization and cytolyic activity of murine cytotoxic T lymphocytes. Exp Cell Res 194:275-283

Kopito RR (2000) Aggresomes, inclusion bodies and protein aggregation. Trends Cell Biol 10:524-530

Kramer ER, Scheuringer N, Podtelejnikov AV, Mann M, Peters JM (2000) Mitotic regulation of the APC activator proteins CDC20 and CDH1. Mol Biol Cell 11:1555-1569

Kramer A, Lukas J, Bartek J (2004) Checking out the centrosome. Cell Cycle 3(11):1390-1393 
Kubo A, Tsukita S (2003) Non-membranous granular organelle consisting of PCM-1, subcellular distribution and cell-cycle-dependent assembly/disassembly. J Cell Sci 116:919-928

Kubo A, Sasaki H, Yuba-Kubo A, Tsukita S, Shiina N (1999) Centriolar satellites: molecular characterization, ATP-dependent movement toward centrioles and possible involvement in ciliogenesis. J Cell Biol 147:969-980

Lacey KR, Jackson PK, Stearns T (1999) Cyclin-dependent kinase control of centrosome duplication. Proc Natl Acad Sci USA 96:2817-2822

Lee J, Miyano T, Moor RM (2000) Spindle formation and dynamics of $\gamma$-tubulin and nuclear mitotic apparatus protein distribution during meiosis in pig and mouse oocytes. Biol Reprod 62:1184-1120

Levy YY, Lai EY, Remillard SP, Heintzelman MB, Fulton C (1996) Centrin is a conserved protein that forms diverse associations with centrioles and MTOCs in Naegleria and other organisms. Cell Motil Cytoskeleton 33:298-323

Lingle WL, Salisbury JL (1999) Altered centrosome structure is associated with abnormal mitoses in human breast tumors. Am J Pathol 155:1941-1951

Lingle WL, Salisbury JL (2000) The role of the centrosome in the development of malignant tumors. Curr Top Dev Biol 49:313329

Lingle WL, Lutz WH, Ingle JN, Maihle NJ, Salisbury JL (1998) Centrosome hypertrophy in human breast tumors: implications for genomic stability and cell polarity. Proc Natl Acad Sci USA 95:2950-2955

Lingle WL, Barrett SL, Negron VC, D'Assoro AB, Boeneman K, Liu W, Whitehead CM, Reynolds C, Salisbury JL (2002) Centrosome amplification drives chromosomal instability in breast tumor development. Proc Natl Acad Sci USA 99:1978-1983

Liu ZH, Schatten H, Hao YH, Lai L, Wax D, Samuel M, Zhong Z-S, Sun Q-Y, Prather RS (2006) The nuclear mitotic apparatus (NuMA) protein is contributed by the donor cell nucleus in cloned porcine embryos. Front Biosci 11:1945-1957

Lohret TA, McNally FJ, Quarmby LM (1998) A role for katanin-mediated axonemal severing during Chlamydomonas deflaggelation. Mol Biol Cell 9:1195-1207

Lutz W, Lingle WL, McCormick D, Greenwood TM, Salisbury JL (2001) Phosphorylation of centrin during the cell cycle and its role in centriole separation preceding centrosome duplication. J Biol Chem 276:20774-20780

Ly DH, Lockhart DJ, Lerner RA, Schultz PG (2000) Mitotic misregulation and human aging. Science 287:2486-2492

Mack GJ, Ou Y, Rattner JB (2000) Integrating centrosome structure with protein composition and function in animal cells. Microsc Res Tech 49:409-419

Manandhar G, Schatten H, Sutovsky P (2005) Centrosome reduction during gametogenesis and its significance. Biol Repro 72:2-13

Mantel C, Braun SE, Reid S, Henegariu O, Liu L, Hangoc G, Broxmeyer HE (1999) p $21^{\text {cip-1/waf-1 }}$-deficiency causes deformed nuclear architecture, centriole overduplication, polyploidy, and relaxed microtubule damage checkpoints in human hematopoietic cells. Blood 93:1390-1398

Marcaillou C, Debec A, Lauverjat S, Saihi A (1993) The effect of heat shock response on ultrastructure of the centrosome of Drosophila cultured cells in interphase: possible relation with changes in the chemical state of calcium. Biochem Cell Biol 71:507-517

Martinez-Campos M, Basto R, Baker J, Kernan M, Raff JW (2004) The Drosophila pericentrin-like protein is essential for cilia/flagella function, but appears indispensable for mitosis. J Cell Biol 165(5):673-678

Martin L, Besch-Williford C, Lai L, Cheong H-T, Im G-S, Park K-W, Murphy C, Hao Y, Ellersieck MR, Keisler DH, Schatten H, Green A, Prather RS (2007) Morphologic and histologic comparisons between in vivo and nuclear transfer derived porcine embryos. Mol Reprod Devel 74:952-960

Matsumoto Y, Maller JL (2002) Calcium, calmodulin, and CaMKII requirement for initiation of centrosome duplication in Xenopus egg extracts (comment). Science 295:499-502

Matsumoto Y, Hayashi K, Nishida E (1999) Cyclin-dependent kinase $2(\mathrm{Cdk} 2)$ is required for centrosome duplication in mammalian cells. Curr Biol 9:429-432

Mayor T, Meraldi P, Stierhof YD, Nigg EA, Fry AM (1999) Protein kinases in control of the centrosome cycle. FEBS Lett 452:92-95

McIntosh JR, Euteneuer U (1984) Tubulin hooks as probes for microtubule polarity: an analysis of the method and an evaluation of data on microtubule polarity in the mitotic spindle. J Cell Biol 98:525-533

McNally FJ, Vale RD (1993) Identification of katanin, an ATPase that severs and disassembles stable microtubules. Cell 75:419-429

McNally FJ, Thomas S (1998) Katanin is responsible for the M-phase microtubule-severing activity in Xenopus eggs. Mol Biol Cell 9:1847-1861

McNally FJ, Okawa K, Iwamatsu A, Vale RD (1996) Katanin, the microtubule-severing ATPase, is concentrated at centrosomes. J Cell Sci 109:561-567

McNally KP, Bazirgan OA, McNally FJ (2000) Two domains of p80 katanin regulate microtubule severing and spindle pole targeting by p60 katanin. J Cell Sci 113:1623-1633

McNaught KS et al (2002) Impairment of the ubiquitin-proteasome system causes dopaminergic cell death and inclusion body formation in ventral mesencephalic cultures. J Neurochem 81:301-306

Megraw TL, Kao LR, Kaufman TC (2001) Zygotic development without functional mitotic centrosomes. Curr Biol 11:116-120

Meraldi P, Nigg EA (2001) Centrosome cohesion is regulated by a balance of kinase and phosphatase activities. J Cell Sci 114:37493757

Meraldi P, Nigg EA (2002) The centrosome cycle. FEBS Lett 521:9_ 13

Meraldi P, Honda R, Nigg EA (2002) Aurora-A overexpression reveals tetraploidization as a major route to centrosome amplification in p53-/-cells. EMBO J 21:483-492

Merdes A, Cleveland DA (1998) The role of NuMA in the interphase nucleus. J Cell Sci 111:71-79

Merdes A, Ramyar K, Vechio JD, Cleveland DW (1996) A complex of NuMA and cytoplasmic dynein is essential for mitotic spindle assembly. Cell 87:447-458

Merdes A, Heald R, Samejima K, Earnshaw WC, Cleveland D (2000) Formation of spindle poles by dynein/dynactin-dependent transport. J Cell Biol 149:851-861

Mogensen MM (1999) Microtubule release and capture in epithelial cells. Biol Cell 91:331-341

Mogensen MM (2004) Microtubule organizing centers in polarized epithelial cells. In: Nigg E (ed) Centrosomes in development and disease. Wiley-VCA Verlag GmbH \& CoKGaG, Weinheim, pp 299-319

Mogensen MM, Malik A, Piel M, Bouckson-Castaing V, Bornens M (2000) Microtubule minus-end anchorage at centrosomal and non-centrosomal sites: the role of ninein. J Cell Sci 113:30133023

Moritz M, Braunfeld MB, Sedat JW, Alberts B, Agard DA (1995) Microtubule nucleation by gamma-tubulin-containing rings in the centrosome. Nature 378:638-640

Moritz M, Zheng Y, Alberts BM, Oegema K (1998) Recruitment of the $\gamma$-tubulin ring complex to Drosophila salt-stripped centrosome scaffolds. J Cell Biol 142:775-786

Moritz M, Braunfeld MB, Guenebaut V, Heuser J, Agard DA (2000) Structure of the gamma-tubulin ring complex: a template for microtubule nucleation. Nat Cell Biol 2:365-370 
Münger K, Duensing S (2004) Radiation therapy and centrosome anomalities in pancreatic cancer. In: Nigg E (ed) Centrosomes in development and disease. Wiley-VCA Verlag GmbH \& $\mathrm{CoK}$ GaG, Weinheim, pp 353-370

Murphy SM, Preble AM, Patel UK, O'Connell KL, Dias DP, Moritz M, Agard D, Stults JT, Stearns T (2001) GCP5 and GCP6: two new members of the human gamma-tubulin complex. Mol Biol Cell 12:3340-3352

Murphy S, Urbani L, Stearns T (1998) The mammalian gamma-tubulin complex contains homologues of yeast spindle pole body component sspc97p and spc98p. J Cell Biol 141:663-674

Nabha SM, Mohammed RM, Dandashi MH, Coupaye-Gerard B, Aboukameel A, Pettit GR, Al-Katib AM (2002) CombretastatinA4 prodrug induces mitotic catastrophe in chronic lymphocytic leukemia cell line independent of caspase activation and poly(ADP-ribose) polymerase cleavge. Clin Cancer Res 8:27352741

Nakahata K, Miyakoda M, Suzuki K, Kodama S, Watanabe M (2002) Heat shock induces centrosomal dysfunction, and causes nonapoptotic mitotic catastrophe in human tumour cells. Int J Hyperthermia 18:332-343

Nigg EA (2004) Centrosomes in development and disease. Wiley$\mathrm{VCH}$, Weinheim

Oakley CD, Oakley BR (1989) Identification of $\gamma$-tubulin, a new member of the tubulin superfamily encoded by mipA gene of Aspergillus nidulans. Nature 338:662-664

Oakley BR, Oakley CE, Yoon Y, Jung MK (1990) Gamma-tubulin is a component of the spindle pole body that is essential for microtubule function in Aspergillus nidulans. Cell 61:1289-1301

Oegema K, Wiese C, Martin OC, Milligan RA, Iwamatsu E, Mitchison TJ, Zheng Y (1999) Characterization of two related Drosophila $\gamma$ tubulin complexes that differ in their ability to nucleate microtubules. J Cell Biol 144:721-733

Ohki R, Nemoto J, Murasawa H, Oda E, Inazawa J, Tanaka N, Taniguchi T (2000) Reprimo, a new candidate mediator of the p53mediated cell cycle arrest at the G2 phase. J Biol Chem 275:22627-22630

Ohta Y, Ohba T, Miyamoto E (1990) $\mathrm{Ca}^{2+} /$ calmodulin-dependent protein kinase II: localization in the interphase nucleus and the mitotic apparatus of mammalian cells. Proc Natl Acad Sci USA 87:5341-5345

Ohta T, Essner R, Ryu JH, Palazzo RE, Uetake Y, Kuriyama R (2002) Characterization of Cep135, a novel coiled-coil centrosomal protein involved in microtubule organization in mammalian cells. J Cell Biol 156:87-99

Ou Y, Rattner JB (2004) The centrosome in higher organisms: structure, composition and duplication. Int Rev Cytol 238:119-182

Palazzo AF, Cook TA, Alberts AS, Gundersen GG (2001) mDia mediates Rho-regulated formation and orientation of stable microtubules. Nat Cell Biol 3:723-729

Pfeiffer D, Gard D (1999) Microtubules in Xenopus oocytes are oriented with their minus-ends towards the cortex. Cell Motil Cytoskeleton 44:34-43

Pietromonaco SF, Seluja GA, Elias L (1995) Identification of enzymatically active $\mathrm{Ca}^{2+}$ /calmodulin-dependent protein kinase in centrosomes of hemopoietic cells. Blood Cells Mol Dis 21:34-41

Pihan GA, Doxsey SJ (1999) The mitoticmachinery is a source of genetic instability in cancer. Semin Cancer Biol 9:289-302

Pihan GA, Wallace J, Zhou Y, Doxsey SJ (2003) Centrosome abnormalities and chromosome instability occur together in pre-invasive carcinomas. Cancer Res 63:1398-1404

Pockwinse SM, Krockmalnic G, Doxsey SJ, Nickerson J, Lian JB, van Wijnen AJ, Stein JL, Stein GS, Penman S (1997) Cell cycle independent interaction of CDC with the centrosome, which is associated with the nuclear matrix-intermediate filament scaffold. Proc Natl Acad Sci USA 94:3022-3027
Prather RS (2000) Perspectives: cloning. Pigs is pigs. Science 289:1886-1887

Prather RS (2007) Nuclear remodeling and nuclear reprogramming for making transgenic pigs by nuclear transfer. In: Sutovsky P (ed) Somatic cell nuclear transfer. Landes Bioscience. Adv Exp Med Biol 591:1-13

Quintyne NJ, Schroer TA (2002) Distinct cell cycle-dependent roles for dynactin and dynein at centrosomes. J Cell Biol 159:245-254

Quintyne NJ, Gill SR, Eckley DM, Crego CL, Compton DA, Schroer TA (1999) Dynactin is required for microtubule anchoring at fibroblast centrosomes. J Cell Biol 147:321-334

Raff JW (2001) Centrosomes:central no more? Curr Biol 11:R159R161

Rattner JB (1991) Hsp70 is localized to the centrosome of dividing HeLa cells. Exp Cell Res 195:110-113

Ripple M, Taylor M, Hueser C, Schatten H (1999) Androgen-responsive $\mathrm{LNCaP}$ and androgen-independent DU 145 prostate cancer cells display different taxol sensitivities. Proc MSA 5(2):1110 1111

Roninson IB, Brude EV, Chang BD (2001) If not apoptosis, then what? Treatment-induced senescence and mitotic catastrophe in tumor cells. Drug Resist Updat 4:303-313

Roth J, Yam GH, Fan J, Hirano K, Gaplovska-Kysela K, Le Fourn V, Guhl B, Santimaria R, Torossi T, Ziak M, Zuber C (2008) Protein quality control: the who's who, the where's and therapeutic escapes. Histochem Cell Biol 129:163-177

Salisbury JL (1995) Centrin, centrosomes, and mitotic spindle poles. Curr Opin Cell Biol 7:39-45

Salisbury JL, Suino KM, Busby R, Springett M (2002) Centrin-2 is required for centriole duplication in mammalian cells. Current Biol 12:1287-1292

Saredi A, Howard L, Compton DA (1997) Phosphorylation regulates the assembly of NuMA in a mammalian mitotic extract. J Cell Sci 110:1287-1297

Sato C, Kuriyama R, Nishizawa K (1983) Microtubule-organizing centers abnormal in number, structure, and nucleating activity in $\mathrm{x}$-irradiated mammalian cells. J Cell Biol 96:776-782

Sato N, Mizumoto K, Nakamura M, Tanaka M (2000a) Radiation-induced centrosome overduplication and multiple mitotic spindles in human tumor cells. Exp Cell Res 255:321-326

Sato N, Mizumoto K, Nakamura M, Ueno H, Minamishima YA, Farber JL, Tanaka M (2000b) A possible role for centrosome overduplication in radiation-induced cell death. Oncogene 19:5281-5290

Sato N, Maitra A, Fukushima N, van Heek NT, Matsubayashi H, Iacobuzio-Donahue CA, Rosty C, Goggins M (2003) Frequent hypomethylation of multiple genes overexpressed in pancreatic ductal adenocarcinoma. Cancer Res 63:4158-4166

Sato N, Mizumoto K, Tanaka M (2004) Radiation therapy and centrosome anomalities in pancreatic cancer. In: Nigg E (ed) Centrosomes in development and disease. Wiley-VCA Verlag GmbH \& CoKGaG, Weinheim, pp 337-352

Saunders WS, Shuster M, Hunag X, Gharaibeh B, Enyenihi AH, Petersen I, Gollin SM (2000) Chromosomal instability and cytoskeletal defects in oral cancer cells. Proc Natl Acad Sci USA 97:303-308

Schatten H, Chakrabarti A (2004) Detection of centrosome structure in fertilized and artificially activated sea urchin eggs using immunofluorescence microscopy and isolation of centrosomes followed by structural characterization with field emission scanning electron microscopy. In: Schatten $\mathrm{H}$ (ed) Methods in molecular biology, vol. 253: germ cell protocols, vol 1: sperm and oocyte analysis. Humana Press, Totowa, pp 151-164

Scaplehorn N, Way M (2004) Manipulation of centrosomes and the microtubule cytoskeleton during infectionbyintracellular pathogens. In: Nigg E (ed) Centrosomes in development and disease. Wiley-VCA Verlag GmbH \& CoKGaG, Weinheim, pp 371-400 
Schatten G (1994) The centrosome and its mode of inheritance: The reduction of centrosome during gametogenesis and its restoration during fertilization. Dev Biol 165:299-335

Schatten H, Schatten G, Mazia D, Balczon R, Simerly C (1986) Behavior of centrosomes during fertilization and cell division in mouse oocytes and in sea urchin eggs. Proc Natl Acad Sci USA 83:105-109

Schatten H, Walter M, Mazia D, Biessmann H, Paweletz N, Coffe G, Schatten G (1987) Centrosome detection in sea urchin eggs with a monoclonal antibody against Drosophila intermediate filament proteins: characterization of stages of the division cycle of centrosomes. Proc Natl Acad Sci USA 84:8488-8492

Schatten H, Ripple M, Balczon R, Taylor M, Crosser M (1998a) Centrosome proliferation in the human androgen-responsive $\mathrm{LNCaP}$ and the androgen-independent DU145 prostate cancer cell lines. Proc Microsc Soc Am 56:1066-1967

Schatten H, Ripple M, Balczon R, Taylor M (1998b) Centrosome abnormalities in cancer cells and tissue. ICEM14. Electron Microsc 4:243-244

Schatten H, Chakrabarti A, Hedrick J (1999a) Centrosome and microtubule instability in cells during aging. J Cell Biochem 74:229241

Schatten H, Wiedemeier A, Taylor M, Lubahn D, Greenberg NM, Besch-Williford C, Rosenfeld C, Day K, Ripple M (1999b) Centrosome and centriole abnormalities during cancer in the transgenic adenocarcinoma mouse prostate (TRAMP) model. Microsc Microanal 5:1152-1153

Schatten H, Hueser CN, Chakrabarti A (2000a) From fertilization to cancer: the role of centrosomes in the union and separation of genomic material. Microsc Res Tech 49:420-427

Schatten H, Ripple M, Balczon R, Weindruch R, Taylor M (2000b) Androgen and taxol cause cell type specific alterations of centrosome and DNA organization in androgen-responsive $\mathrm{LNCaP}$ and androgen-independent prostate cancer cells. J Cell Biochem 76:463-477

Schatten H, Wiedemeier A, Taylor M, Lubahn D, Greenberg MN, Besch-Williford C, Rosenfeld C, Day K, Ripple M (2000c) Centrosome-centriole abnormalities are markers for abnormal cell divisions and cancer in the transgenic adenocarcinoma mouse prostate (TRAMP) model. Biol Cell 92:331-340

Schatten H, Hueser C, Chakrabarti A (2000d) Centrosome alterations induced by formamide cause abnormal spindle pole formations. Cell Biol Int 24(9):611-620

Schatten H, Prather RS, Sun QY (2005) The significance of mitochondria for embryo development in cloned arm animals. Mitochondrion 5(5):303-321

Sibon OC, Kelkar A, Lemstra W, Theurkauf WE (2000) DNA/replication/DNA-damage-dependent centrosome inactivation in Drosophila embryos. Nat Cell Biol 2:90-95

Simerly C, Dominko T, Navara CS (2003) Molecular correlates of primate nudear transfer failures. Science 300(5617):297

Sluder G (2004) Centrosome duplication and its regulation in the higher animal cell. In: Nigg E (ed) Centrosomes in development and disease. Wiley-VCA Verlag GmbH \& CoKGaG, Weinheim, pp $167-189$

Schroer TA (2001) Microtubules don and doff their caps: dynamic attachments at plus and minus ends. Curr Opin Cell Biol 13:92-96

Steadman BT, Schmidt PH, Shanks RA, Lapierre LA, Goldenring JR (2002) Transforming acidic coiled-coil-containing protein 4 interacts with centrosomal AKAP350 and the mitotic spindle apparatus. J Biol Chem 277(33):30165-30176

Sun QY, Schatten H (2006) Multiple roles of NuMA in vertebrate cells: Review of an intriguing multi-functional protein. Front Biosci 11:1137-1146

Sun QY, Schatten H (2007) Centrosome inheritance after fertilization and nuclear transfer in mammals. In: Sutovsky P (ed) Somatic cell nuclear transfer. Landes Bioscience. Adv Exp Med Biol 591:58_ 71

Sun QY, Lai L, Park KW, Kühholzer B, Prather RS, Schatten H (2001a) Dynamic events are differently regulated by microfilaments, microtubules, and mitogen-activated protein kinase during porcine oocyte maturation and fertilization in vitro. Biol Reprod 64:879-889

Sun QY, Lai L, Bonk A, Prather RS, Schatten H (2001b) Cytoplasmic changes in relation to nuclear maturation and early embryo developmental potential of porcine oocytes: effects of gonadotropins, cumulus cells, follicular size and protein synthesis inhibition. Mol Reprod Dev 59:192-198

Sun Q-Y, Lai L, Wu G, Park K-W, Day B, Prather RS, Schatten H (2001c) Microtubule assembly after treatment of pig oocytes with taxol: correlation with chromosomes, $\gamma$-tubulin and MAP kinase. Mol Reprod Dev 60:481-490

Sun Q-Y, Wu GM, Lai L, Park KW, Day B, Prather RS, Schatten H (2001d) Translocation of active mitochondria during porcine oocyte maturation, fertilization and early embryo development in vitro. Reproduction 122:155-163

Sun Q-Y, Lai L, Wu G, Bonk A, Cabot R, Park K-W, Day B, Prather RS, Schatten H (2002) Regulation of mitogen-activated protein kinase phosphorylation, microtubule organization, chromatin behavior, and cell cycle progression are regulated by protein phosphatases during pig oocyte maturation and fertilization in vitro. Biol Reprod 66(3):580-588

Takahashi M, Yamagiwa A, Nishimura T, Mukai H, Ono Y (2002) Centrosomal proteins CG-NAP and kendrin provide microtubule nucleation sites by anchoring gamma-tubulin ring complex. Mol Biol Cell 13:3235-3245

Tassin AM, Bornens M (1999) Centrosome structure and microtubule nucleation in animal cells. Biol Cell 91:343-354

Tassin AM, Celati C, Moudjou M, Bornens M (1998) Characterization of the human homologue of the yeast Spc98p and its association with gamma-tubulin. J Cell Biol 141:689-701

Thompson-Coffe C, Coffe G, Schatten H, Mazia D, Schatten G (1996) Cold-treated centrosome: isolation of centrosomes from mitotic sea urchin eggs, production of an anticentrosomal antibody, and novel ultrastructural imaging. Cell Motil Cytoskeleton 33:197207

Tong C, Fan H-Y, Lian L, Li S-W, Chen D-Y, Schatten H, Sun Q-Y (2002) Polo-like kinase-1 is a pivotal regulator of microtubule assembly during mouse oocyte meiotic maturation, fertilization, and early embryonic mitosis. Biol Reprod 67:546-554

Tong C, Fan H-Y, Li S-W, Chen D-Y, Song X-F, Schatten H, Sun QY (2003) Effects of MEK inhibitor U0126 on meiotic progression in mouse oocytes: microtuble organization, asymmetric division and metaphase II arrest. Cell Res 13(5):375-383

Tulu US, Rusan NM, Wadsworth P (2003) Peripheral, non-centrosome-associated microtubules contribute to spindle formation in centrosome-containing cells. Curr Biol 13:1894-1899

Tugendreich S, Tomkiel J, Earnshaw W, Hieter P (1995) CDC27Hs colocalizes with $\mathrm{CDC} 16 \mathrm{Hs}$ to the centrosome and mitotic spindle and is essential for the metaphase to anaphase transition. Cell 81:261-268

Van Beneden E (1876) Contribution al'histoire de la vesiculaire germinative et du premier embryonnaire. Bull Acad R Belg 42:35-97

Vogl AW, Weis M, Pfeiffer DC (1995) The perinuclear centriole-containing centrosome is not the major microtubule organizing center in Sertoli cells. Eur J Cell Biol 66:165-179

Vidair CA, Doxsey SJ, Dewey WC (1993) Heat shock alters centrosome organization leading to mitotic dysfunction and cell death. J Cell Physiol 154:443-455

Vidair CA, Doxsey SJ, Dewey WC (1995) Thermotolerant cells possess an enhanced capacity to repair heat-induced alterations to centrosome structure and function. J Cell Physiol 163:194-203 
Vidair CA, Huang RN, Doxsey SJ (1996) Heat shock causes protein aggregation and reduced protein solubility at the centrosome and other cytoplasmic locations. Int J Hyperthermia 12:681-695

Wang Q, Xie S, Chen J, Fukasawa K, Naik U, Traganos F, Darzynkiewicz Z, Jhanwar-Uniyal M, Dai W (2002) Cell cycle arrest and apoptosis by human polo-like kinase 3 is mediated through perturbation of microtubule integrity. Mol Cell Biol 22(10):3450 3459

Wakefield J, Huang J-Y, Raff JW (2000) Centrosomes have a role in regulating the destruction of cyclin B in early Drosophila embryos. Curr Biol 10:1367-1370

Walczak CE, Vernos I, Mitchison TJ, Karsenti E, Heald R (1998) A model for the proposed roles of different microtubule-based motor proteins in establishing spindle bipolarity. Curr Biol 8:903-913

Welte MA (2004) Bidirectional transport along microtubules. Curr Biol 14(13):R525-R537

Wilkinson CJ, Andersen JS, Mann M, Nigg EA (2004) A proteomic approach to the inventory of the human centrosome. In: Nigg E (ed) Centrosomes in development and disease. Wiley-VCA Verlag GmbH \& CoKGaG, Weinheim, pp 125-142

Wojcik C, DeMartino GN (2003) Intracellular localization of proteasomes. Int J Biochem Cell Biol 35:579-589
Wong C, Stearns T (2003) Centrosome number is controlled by a centrosome-intrinsic block to reduplication. Nat Cell Biol 5:539-544

Xu X, Weaver Z, Linke SP, Li C, Gotay J, Wang XW, Harris CC, Ried T, Deng CX (1999) Centrosome amplification and a defective G2$M$ cell cycle checkpoint induce genetic instability in BRCA1 exon 11 isoform-deficient cells. Mol Cell 3:389-395

Young A, Dictenberg JB, Purohit A, Tuft R, Doxsey SJ (2000) Cytoplasmic dynein-mediated assembly of pericentrin and $\gamma$ tubulin onto centrosomes. Mol Biol Cell 11:2047-2056

Zeng C (2000) NuMA: a nuclear protein involved in mitotic centrosome function. Microsc Res Tech 49:467-477

Zheng Y, Wong ML, Alberts B, Mitchison T (1995) Nucleation of microtubule assembly by a gamma-tubulin-ring complex. Nature 378:578-583

Zhong Z-S, Zhang G, Meng X-Q, Zhang Y-L, Chen D-Y, Schatten H, Sun Q-Y (2005) Function of donor cell centrosome in intraspecies and interspecies nuclear transfer embryos. Exp Cell Res 306:35-46

Zhong Z, Spate L, Hao Y, Li R, Lai L, Katayama M, Sun Q-Y, Prather $\mathrm{R}$, Schatten H (2007) Remodeling of centrosomes in intraspecies and interspecies nuclear transfer porcine embryos. Cell Cycle 6(12):1510-1521 